\title{
Asset Price Beliefs And Optimal Monetary Policy
}

\author{
Colin Caines and Fabian Winkler* \\ Federal Reserve Board
}

February 14, 2019

\begin{abstract}
We characterize optimal monetary policy when agents have extrapolative beliefs about asset prices. Such boundedly rational expectations induce inefficient asset price and aggregate demand fluctuations. We find that the optimal monetary policy raises interest rates when expected capital gains or the level of current asset prices is high, but does not eliminate deviations of asset prices from their fundamental value. When the asset is in elastic supply, optimal policy also leans against the wind, tolerating low inflation and output when asset prices are too high. Optimal policy can be reasonably approximated by simple interest rate rules that respond to capital gains. Our results are robust to a wide range of belief specifications.
\end{abstract}

Keywords: Optimal Monetary Policy, Natural Real Interest Rate, Learning, Asset Price Volatility, Leaning Against The Wind

JEL codes: E44, E52

\footnotetext{
${ }^{*}$ Board of Governors of the Federal Reserve System, 20th St and Constitution Ave NW, Washington DC 20551. Email address: colin.c.caines and fabian.winkler, both @frb.gov. We thank Chris Gust, Damjan Pfajfar, Chris Erceg, Kevin Lansing, Thomas Mertens, Robert Tetlow, and seminar participans at the Chicago Fed, the San Francisco Fed, Drexel University, the 2018 Midwest Macro conference, the 2018 Canadian Economics Assocation Meetings and and the 2018 Econometric Society Summer Meeting for helpful comments. The views herein are solely the responsibility of the authors and should not be interpreted as reflecting the views of the Board of Governors of the Federal Reserve System or of any other person associated with the Federal Reserve System.
} 


\section{Introduction}

How, if at all, should monetary policy react to asset prices? Some argue that asset price misalignments can pose significant risks to macroeconomic and financial stability, and that monetary policy should raise interest rates in response to asset price increases to stabilize business cycles. Others argue that monetary policy should not pay attention at all to asset prices, or at most in order to improve forecasts of inflation and economic activity.

Any answer to this question depends on what is assumed about the sources of asset price fluctuations. Are financial markets pricing assets efficiently, and if not, what is the nature of price misalignments? Standard macroeconomic models, including workhorse New-Keynesian models used for monetary policy analysis, embody the efficient market hypothesis that rules out asset price misalignments by design. Recently, Gali $(2014,2017)$ has added rational bubbles to these models, recommending a negative reaction of interest rates to asset prices because rational bubbles grow more slowly at lower interest rates. Yet rational bubbles are not the only way through which asset prices can deviate from their "fundamental value". An alternative narrative of price misalignments holds that investors have boundedly rational expectations and suffer from bouts of over- and under-confidence which affect prices. This narrative can be formalized through models of learning, which are a plausible explanation for many well-known asset price characteristics (Fuster et al. 2012; Collin-Dufresne et al. 2013; Adam et al. 2015; Barberis et al. 2015 for stock prices; Adam et al. (2012); Caines (2016); Glaeser and Nathanson (2017) for house prices). Moreover, these models are consistent with survey measures of return expectations that are at odds with rational expectations (Greenwood and Shleifer, 2014). However, very little work exists on how boundedly rational asset price expectations affect the conduct of monetary policy.

In this paper, we solve for optimal monetary policy in a model in which agents hold subjective, boundedly rational beliefs about asset prices and update these beliefs through a standard learning process. The model is a simple New-Keynesian model, to which we add a durable asset in fixed supply and learning about the equilibrium asset price. The learning process implies extrapolative expectations and endogenous boom-bust cycles in equilibrium price dynamics. These fluctuations have real effects because they change subjective wealth and therefore spending and investment decisions, even though agents perfectly observe the fundamental state of the economy. We isolate the effects of asset price learning from other expectational channels by restricting expectations to be model-consistent conditional on subjective asset price beliefs (Winkler, 2016). This restriction effectively implies that expectations are consistent with all 
equilibrium conditions other than asset market clearing. ${ }^{1}$ In particular, it implies that agents correctly understand the monetary transmission mechanism save for its effect on asset prices.

When the asset is in fixed supply, we show that the natural real rate of interest is not only a function of technology and preferences, but depends positively on subjective asset price beliefs. The intuition for this result is simple: When agents expect larger capital gains on the asset, then the return on bonds must also rise for the bond market to clear, even if the capital gains expectations aren't rational. We show that in terms of target criteria, flexible inflation targeting remains optimal under learning. But in order to implement this target, the central bank needs to raise interest rates when asset prices are high, independently of the fundamental shocks hitting the economy.

When we also allow for an elastic supply of the asset, we find that the optimal policy "leans against the wind" in the sense of Svensson (2017): The central bank is willing to tolerate low inflation if either current or future expected asset prices are inefficiently high, even when the output gap is closed. This is not the case in the rational expectations version of the model.

Finally, we numerically evaluate simple Taylor-type interest rate rules with a reaction to asset prices. We find that a positive asset price reaction generally mitigates the distortions from non-rational beliefs and stabilizes asset price fluctuations. This finding is in contrast to Gali (2014) and Dong et al. (2017) in which a positive reaction of interest rate to asset prices exacerbates the volatility of rational bubbles.

When we analyze optimal policy, we assume that the central bank maximizes welfare under the objective probability distribution, not under the subjective distribution of boundedly rational agents. Such a paternalistic objective does not imply that the central bank has superior knowledge of the economy, but merely that it has a different view of the economy than the private sector. Insofar as central banks' views on asset prices do diverge from those of financial markets-like those expressed in Alan Greenspan's "irrational exuberance" comments (Greenspan, 1996)—our analysis is of practical importance.

Our baseline model assumes a particular process of expectation formation in which agents think that asset prices are a random walk with a small time-varying drift. This process has been shown to fit the data well (Adam et al., 2017), but our results are not confined to this choice. We show that our results carry through to a more general class of subjective beliefs, including "natural expectations" (Fuster et al., 2012) and "diagnostic expectations" (Bordalo et al., 2018). Another assumption we make is that ex-

\footnotetext{
${ }^{1}$ The concept has also been applied in Caines (2016) and Gandré (2017).
} 
pectations are model-consistent conditionally on asset price beliefs. This restriction greatly reduces the degrees of freedom for boundedly rational expectations. However, we do not mean to imply that belief distortions or learning about other aspects of the economy, such as inflation or even monetary policy itself, do not matter. Rather, we see this assumption as a modeling device that allows us to isolate the effects of asset price learning from other such distortions.

In our model, subjective asset price beliefs have real effects because they affect subjective wealth. This wealth effect channel can be seen as a stand-in for more complex transmission channels of asset prices, such as credit constraints and balance sheet effects. The advantage of this simplification is that we are able to obtain closed form solutions for optimal monetary policy in the presence of learning.

A central prediction of our model is that the natural real interest rate and the level of asset prices are positively related. Such a relationship is supported by empirical measures of the natural real rate, as Figure 1 shows. The figure plots the 20-quarter change in the Laubach and Williams (2016) natural rate estimate against the 20-quarter change in both the FHFA house price index and the Shiller CAPE ratio. ${ }^{2}$ Asset prices and the natural real rate are positively correlated in both cases.

Figure 1: 20-Quarter Change in the Natural Rate of Interest \& Asset Prices.
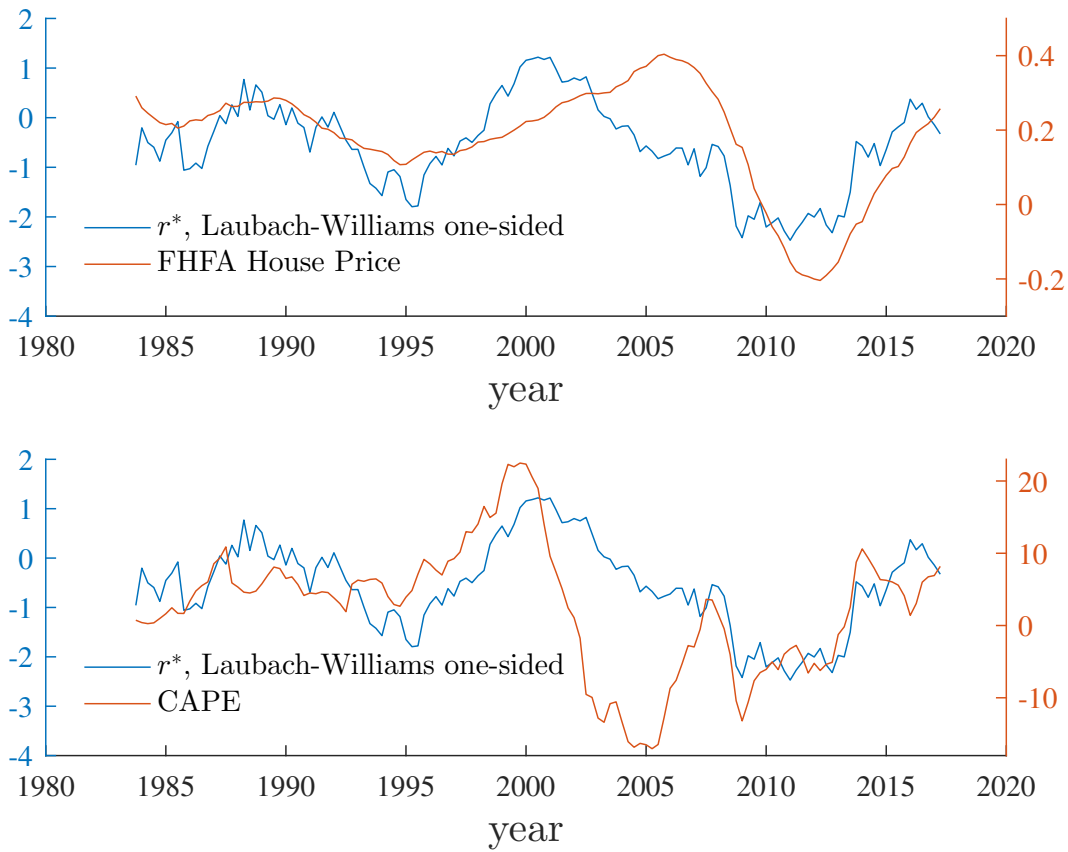

The paper most closely related to our analysis is Adam and Woodford (2018), who study "robustly optimal policy" in a New-Keynesian model with house prices. The rational

\footnotetext{
${ }^{2}$ We thank Kevin Lansing for pointing out this relationship to us.
} 
expectations version of their model is almost identical to ours, ${ }^{3}$ but the deviation from rational expectations and the policy problem are quite different. Adam and Woodford study distortions to the beliefs about the fundamentals of the economy (e.g. preferences and technology), and let the policymaker choose a policy that maximizes welfare for the worst possible realization of these distortions. An important appeal of this approach is that the policymaker's ability to exploit distorted expectations to its advantage is limited, because the class of possible distortions is large and the policymaker does not know which of them is realized. In that framework, Adam and Woodford find that a positive reaction of interest rates to asset prices is beneficial if the steady state is distorted in a particular direction. Our results hold at the fully efficient steady state. Agents do know the fundamentals of the economy, but hold misspecified beliefs about an endogenous variable. The policymaker knows the form of this distortion, but we limit the degree to which she can exploit it, by requiring that private sector agents must have model-consistent expectations for the policymaker's target process for inflation.

Our analysis shares some features with Christiano et al. (2010), who study the optimal policy reaction to news shocks about future productivity. In their model, news shocks cause asset prices to rise, and also increase the natural real rate of interest, so that monetary policy should optimally respond by raising interest rates. In this paper, the natural real rate fluctuates in response to endogenous changes in subjective expectations that do not rely on exogenous news shocks.

Previous studies have argued for a monetary policy reaction to asset prices in environments without rational expectations, for example Dupor (2005) and Mertens (2011). In these studies, beliefs about the exogenous fundamentals of the economy are distorted, and affect welfare through an investment channel. To our knowledge, our analysis is the first in which beliefs about the asset price itself—an endogenous variable-are distorted. We find departures from the optimal policy under rational expectations even when there is no investment channel.

We also complement a growing literature studying monetary policy prescriptions in models with learning. Fully optimal policy has recently been studied in a two-equation model with learning by Molnar and Santoro (2014) and Eusepi and Preston (2016). Eusepi et al. (2015) introduce drift in long-run expectations to a New Keynesian model and show that such beliefs introduce a policy tradeoff between stabilizing current inflation and anchoring long-horizon beliefs. In these papers, asset prices are absent

\footnotetext{
${ }^{3}$ One important difference is that utility is linear in housing in their model. This effectively implies that the level of housing wealth does not enter the model as a state variable. In our learning model, changes in subjective wealth are the key distortion induced by non-rational asset price expectations, and hence we cannot make the same assumption. Instead, we solve for optimal policy carrying endogenous state variables.
} 
and it is mostly learning about the inflation process that drives the dynamics of the model. ${ }^{4}$ Instead, we focus on non-rational asset price beliefs, while endowing agents with conditionally consistent beliefs about the rest of the economy.

The remainder of this paper is structured as follows. We begin by describing the baseline model in Section 2, and our notion of a learning equilibrium in Section 3. We characterize the linearized equilibrium under rational expectations and learning in Section 4. Optimal policy is analyzed in Sections 5, while Section 6 discusses how well certain simple interest rate rules approximate the optimal policy. Sections 7 and 8 discuss extensions to more general beliefs and elastic housing supply, respectively. Section 9 concludes.

\section{Model description}

Our model is a standard New-Keynesian model in which the representative household also holds a stock of an asset that yields utility. The supply of the asset in the economy is fixed. One can think of the asset as a stock of housing, but we will refer to it as a generic durable asset. Because the asset is in fixed supply, the dynamics of inflation and output are unaffected by its presence under rational expectations. Under learning, however, we will get non-trivial effects of asset prices on allocations.

We first describe the model for a general description of expectations. A representative household provides labor and owns firms. It can also hold nominal bonds promising a nominal return $i_{t}$. In addition, the household owns the durable asset. The household's problem is

$$
\begin{gathered}
\qquad \mathbb{E}^{\mathscr{P}} \sum_{t=0}^{\infty} \beta^{t}\left(\frac{C_{t}^{1-\gamma}}{1-\gamma}-\frac{N_{t}^{1+\phi}}{1+\phi}+\chi \frac{H_{t}^{1-\theta}}{1-\theta}\right) \\
\text { s.t. } C_{t}=W_{t} N_{t}+\Pi_{t}+T_{t}-Q_{t}\left(H_{t}-H_{t-1}\right)+B_{t}-\frac{1+i_{t-1}}{1+\pi_{t}} B_{t-1} .
\end{gathered}
$$

Here, $C_{t}$ is the household's utility from consuming final consumption goods, $N_{t}$ is the household's labor supply, and $T_{t}$ are lump-sum taxes. $\Pi_{t}$ are the profits received from firms. The quantity of the asset owned by the household is denoted $H_{t}$ and trades at the price $Q_{t}$. $B_{t}$ are government bonds which are in zero net supply. The price level is $P_{t}$ and $\pi_{t}=P_{t} / P_{t-1}-1$ is the inflation rate. The expectational operator $\mathbb{E}^{\mathscr{P}}$

\footnotetext{
${ }^{4}$ Airaudo (2016) aguments the standard New Keynesian model with a stock market and infinitehorizon learning as in Preston (2006) to study conditions under which the rational expectations equilibrium is learnable, but stops short of characterizing optimal policy.
} 
has a superscript indicating that agents' expectations are evaluated under a subjective probability measure $\mathscr{P}$ that need not coincide with rational expectations.

The first order conditions are:

$$
\begin{aligned}
W_{t} & =C_{t}^{\gamma} N_{t}^{\phi} \\
1 & =\beta \mathbb{E}_{t}^{\mathscr{P}}\left(\frac{C_{t}}{C_{t+1}}\right)^{\gamma} \frac{1+i_{t}}{1+\pi_{t+1}} \\
Q_{t} & =\chi \frac{C_{t}^{\gamma}}{H_{t}^{\theta}}+\beta \mathbb{E}_{t}^{\mathscr{P}}\left(\frac{C_{t}}{C_{t+1}}\right)^{\gamma} Q_{t+1} .
\end{aligned}
$$

On the production side, a representative intermediate goods producer transforms household labor into intermediate goods using the decreasing returns to scale technology

$$
\tilde{Y}_{t}=A_{t} N_{t}^{\alpha}
$$

It has to hire labor at the real wage rate $w_{t}$ and sells its goods at the real price $M_{t}$. Its first-order condition is

$$
W_{t}=\alpha M_{t} A_{t} N_{t}^{\alpha-1}
$$

There is a contiuum of wholesalers indexed by $i \in[0,1]$ who transform the undifferentiated intermediate good into differentiated goods using a one-for-one technology. They face a standard Dixit-Stiglitz demand function and a Calvo price setting friction. When producer $i$ is able to set a price $P_{i t}$ for its output $Y_{i t}$, it solves:

$$
\begin{gathered}
\max _{P_{i t}} \mathbb{E}_{t}^{\mathscr{P}} \sum_{s=0}^{\infty}\left(\prod_{\tau=1}^{s} \xi \Lambda_{t, t+\tau}\right)\left(\left(1+\tau_{t}\right) P_{i t}-M_{t+s} P_{t+s}\right) Y_{i t+s} \\
\text { s.t. } Y_{i t}=\left(\frac{P_{i t}}{P_{t}}\right)^{-\sigma} Y_{t},
\end{gathered}
$$

where $\sigma$ is the demand elasticity of substitution between varieties, $\Lambda_{t, t+\tau}=\beta^{\tau} C_{t}^{\gamma} C_{+\tau}^{-\gamma}$ is the household discount factor between times $t$ and $t+\tau$, $\xi$ is the probability of not being able to adjust the price in the future. Any profits are distributed to households. The first-order conditions are standard and give rise to the New-Keynesian Phillips curve.

The term $\tau_{t}$ is a time-varying government subsidy to revenue. Shocks to the subsidy will act as cost-push shocks. The steady-state value of the subsidy is set such that it eliminates mark-up distortions. Our steady state is therefore fully efficient.

A representative retailer buys differentiated goods from wholesalers at the price $P_{i t}$ and transforms them back into a homogenous final consumption good. The final good 
sells at price $P_{t}$ and is produced according to the technology

$$
Y_{t}=\left(\int_{0}^{1}\left(Y_{i t}\right)^{\frac{\sigma-1}{\sigma}} d i\right)^{\frac{\sigma}{\sigma-1}}
$$

The first order condition gives rise to a constant elasticity of substitution $\sigma$ between varieties. The price level can be expressed as $P_{t}=\int_{0}^{1} P_{i t} Y_{i t} / Y_{t}$.

The government transfers a lump sum real amount to households

$$
T_{t}=\tau_{t} \int_{0}^{1} P_{i t} Y_{i t} d i
$$

to finance the subsidies to final good producers and offset the tax on stock holdings. Profits and government transfers sum up to $\Pi_{t}+T_{t}=Y_{t}-W_{t} N_{t}$. Finally, the central bank sets the nominal interest rate. Throughout the paper, we will assume that the central bank specifies monetary policy to guarantee uniqueness and determinacy of the equilibrium. We also abstract from the zero lower bound on nominal interest rates. Aggregate fluctuations are caused by productivity and, potentially, cost-push shocks, which follows first-order autoregressive processes:

$$
\begin{aligned}
\log A_{t} & =\left(1-\rho_{a}\right) \log \bar{A}+\rho_{a} \log A_{t-1}+\varepsilon_{a t} \\
\tau_{t} & =\left(1-\rho_{\tau}\right) \bar{\tau}_{t}+\rho_{\tau} \tau_{t-1}+\varepsilon_{\tau t}
\end{aligned}
$$

The innovations are independent white noise with variances $\sigma_{A}^{2}$ and $\sigma_{\tau}^{2}$.

Market clearing in the final goods market requires $Y_{t}=C_{t}$. Bonds are in zero net supply and the market clearing condition is therefore $B_{t}=0$. Finally, the supply of the durable is fixed at unity, so that asset market clearing requires $H_{t}=1$.

\section{Equilibrium}

The equilibrium under rational expectations is standard-it is the textbook New Keynesian model. The asset price $Q_{t}$ is redundant because the durable asset is in fixed supply. Agents with rational expectations never expect to buy or sell the asset, not because they expect to be unable to to do so-they are price takers in a competitive market-but because they expect the price in every state of the world to be such that they will not ever want to change their asset holdings.

Let's recall the formal definition of a rational expectations equilibrium. Let $y_{t} \in \mathbb{R}^{N}$ denote the collection of all endogenous model variables-including prices, allocations, 
and strategies—and by $u_{t} \in \mathbb{R}^{M}$ the collection of all exogenous model variables at time $t$, which I will call "fundamentals". Stochastic processes for $y_{t}$ and $u_{t}$ are defined on the spaces $\Omega_{y}=\prod_{t=0}^{\infty} \mathbb{R}^{N}$ and $\Omega_{u}=\prod_{t=0}^{\infty} \mathbb{R}^{M}$, respectively. Further, denote by $\Omega_{u}^{(t)}$ the set of all possible histories of exogenous variables up to period $t$, and its elements by $u^{(t)} \in \Omega_{u}^{(t)}$. Finally, let $\mathbb{P}_{u}$ denote the true probability measure for the exogenous variables defined on $\left(\Omega_{u}, \mathscr{S}\left(\Omega_{u}\right)\right)$, where $\mathscr{S}(\cdot)$ is the Borel sigma-algebra on a metric space. The topological support of $\mathbb{P}_{u}$ is denoted bysupp $\left(\mathbb{P}_{u}\right)$.

Definition 1. A rational expectations equilibrium is a sequence of mappings $g_{t}: \Omega_{u}^{(t)} \ni$ $u^{(t)} \mapsto y_{t} \in \mathbb{R}^{N}, t=0,1,2, \ldots$ such that, for all $t$ and $u^{(t)} \in \operatorname{supp}\left(\mathbb{P}_{u}\right)$ :

1. the choices contained in $y_{t}$ solve the time- $t$ decision problem of each agent in the economy, conditional on decision-relevant ${ }^{5}$ past and current outcomes contained in $u^{(t)}$ and $y^{(t)}=\left(g_{0}\left(u^{(0)}\right), \ldots, g_{t}\left(u^{(t)}\right)\right)$, and evaluating the probability of future external decision-relevant outcomes under the probability measure $\mathbb{P}_{R E}$ implied by $\mathbb{P}_{u}$ and the mappings $\left(g_{t}\right)_{t=0}^{\infty}$;

2. the allocations contained in $y_{t}=g_{t}\left(u^{(t)}\right)$ clear all markets.

Under learning, we assume that agents are not endowed with the knowledge of the equilibrium asset price process. Intuitively, they do not know whether only the representative household is investing in the asset, or whether other investors exist who trade in unknown ways, causing seemingly random price fluctuations. Faced with this lack of knowledge, agents forecast prices using a subjective belief system. As we show in Section 7 , this subjective belief system can be made quite general, but here we confine ourselves to our preferred specification which follows Adam et al. (2017). Agents think that the asset price is a simple random walk model with a time-varying drift:

$$
\begin{aligned}
\Delta \log Q_{t} & =\mu_{t-1}+\varepsilon_{t} \\
\mu_{t} & =\rho_{\mu} \mu_{t-1}+v_{t} .
\end{aligned}
$$

where $0<\rho_{\mu}<1$ and the shocks $\varepsilon_{t} \sim \mathscr{N}\left(0, \sigma_{\varepsilon}^{2}\right)$ and $v_{t} \sim \mathscr{N}\left(0, \sigma_{v}^{2}\right)$ are iid white noise, independent of the rest of the economy. Since these two shocks are not observable, agents have to use the Kalman filter to form a belief about the hidden state $\mu_{t}$. The

\footnotetext{
${ }^{5} \mathrm{~A}$ variable is decision-relevant if it enters the agents' decision problem, and a decision-relevant variable is external if its value is taken as given by the agent, while it is internal if the variable is part of the solution of the agents' decision problem. For example, wholesalers need to get information on current and future aggregate demand $Y_{t}$ (decision-relevant and external) to set prices $P_{i t}$ (decision-relevant and internal), while they do not need to forecast wages since their only production input is the intermediate good.
} 
asset price can equivalently be written just in terms of observables and the filtered state:

$$
\begin{aligned}
\Delta \log Q_{t} & =\hat{\mu}_{t-1}+z_{t} \\
\hat{\mu}_{t} & =\rho_{\mu} \hat{\mu}_{t-1}+g z_{t}
\end{aligned}
$$

Here, $\hat{\mu}_{t}$ is the belief about $\mu_{t} ; g$ is the weight agents place on new data when updating their beliefs, which is a function of the perceived variances of $\varepsilon_{t}$ and $v_{t}$; and $z_{t} \sim \mathscr{N}\left(0, \sigma_{z}^{2}\right)$ is the forecasting error in the filtering problem. This forecasting error is exogenous normally distributed white noise under agents' subjective expectation, the variance of which is decreasing in the signal-to-noise ratio $\sigma_{v}^{2} / \sigma_{\varepsilon}^{2}$. In order to avoid complications arising from simultaneity in the determination of outcomes and beliefs, we follow Adam et al. (2012) and Caines (2016) and assume that in period $t$ agents make choices conditional on $\hat{\mu}_{t-1}$, and update their beliefs according to (3) at the end of the period.

In order to determine expectations about the remaining variables of the model, including inflation, we follow Winkler (2016) in assuming that agents have so-called "conditionally model-consistent expectations". This is a restriction on expectations that effectively allows us to isolate the effects of asset price learning from other potential sources of learning in the economy. Conditionally model-consistent expectations are consistent with all equilibrium conditions of the model, except those that would convey knowledge of the price that clears the asset market.

Formally, let $\left(\Omega_{z}, \mathscr{S}\left(\Omega_{z}\right), \mathscr{P}_{z}\right)$ be the probability space that defines the subjective beliefs for $z_{t}$ (i.e., the $z_{t}$ are iid normally distributed with mean zero and variance $\sigma_{z}^{2}$ ). Agents' subjective beliefs depend on this perceived stochastic forecast error even though in equilibrium, model outcomes are a function only of fundamentals $u_{t}$. The subjective probability measure $\mathscr{P}$ is defined by a mapping from fundamentals $u_{t}$ and the subjective forecast error $z_{t}$ to model outcomes $y_{t}$.

Definition 2. Conditionally model-consistent expectations (CMCE) are a sequence of mappings $h_{t}: \Omega_{u}^{(t)} \times \Omega_{z}^{(t)} \ni\left(u^{(t)}, z^{(t)}\right) \mapsto y_{t} \in \mathbb{R}^{N}, t=0,1,2, \ldots$ such that, for all $t$ and $\left(u^{(t)}, z^{(t)}\right) \in \operatorname{supp}\left(\mathscr{P}_{u, z}\right)$ :

1. the choices contained in $y_{t}$ solve the time- $t$ decision problem of each agent in the economy, conditional on decision-relevant past and current outcomes contained in $u^{(t)}$ and $y^{(t)}=\left(h_{0}\left(u^{(0)}, z^{(0)}\right), \ldots, h_{t}\left(u^{(t)}, z^{(t)}\right)\right)$, and evaluating the probability of future decision-relevant outcomes under the probability measure $\mathscr{P}$ implied by $\mathbb{P}_{u} \otimes \mathscr{P}_{z}$ and the mappings $\left(h_{t}\right)_{t=0}^{\infty}$; 
2. the allocations contained in $y_{t}=h_{t}\left(u^{(t)}, z^{(t)}\right)$ clear all markets except the markets for assets and final consumption goods;

3. asset prices under $\mathscr{P}$ follow the law of motion given by (3)-(4).

The definition of the mappings $h_{t}$ defining expectations is almost identical to the definition of a rational expectations equilibrium, except that asset market equilibrium is not part of the conditions, and instead the price $Q_{t}$ evolves according to subjective beliefs $^{6}$. Conditional model consistency restricts the subjective belief $\mathscr{P}$ to have the maximum degree of consistency with the model given agents' misspecified belief about asset prices. In analogy to the adaptive learning literature, we call the mappings $h_{t}$ defining beliefs the perceived law of motion (PLM).

Computing the learning equilibrium is an easy two-step procedure: First, compute the $\operatorname{PLM} h_{t}\left(u^{(t)}, z^{(t)}\right)$; second, compute the ALM $g_{t}\left(u^{(t)}\right)$. Both steps are no more complicated than solving the rational expectations equilibrium.

While under $\mathscr{P}$, demand for the durable asset does not have to be equal to supply, in equilibrium the market still has to clear:

Definition 3. An equilibrium with conditionally model-consistent expectations is a sequence of mappings $r_{t}: \Omega_{u}^{(t)} \ni u^{(t)} \mapsto z_{t} \in \mathbb{R}$ and $g_{t}: \Omega_{u}^{(t)} \ni u^{(t)} \mapsto y_{t} \in \mathbb{R}^{N}, t=0,1,2, \ldots$ such that, for all $t$ and $u^{(t)} \in \operatorname{supp}\left(\mathbb{P}_{u}\right)$ :

1. $g\left(u^{(t)}\right)=h\left(u^{(t)},\left(r_{0}\left(u^{(0)}\right), \ldots, r_{t}\left(u^{(t)}\right)\right)\right)$;

2. the allocations contained in $y_{t}=g_{t}\left(u^{(t)}\right)$ clear the asset market.

The probability measure implied by $\mathbb{P}_{u}$ and the mappings $\left(g_{t}\right)_{t=0}^{\infty}$ is denoted by $\mathbb{P}$.

Market clearing is brought about by finding the right value of the price $Q_{t}$ that clears the housing market. We call the resulting equilibrium mappings $g_{t}$ the actual law of motion (ALM). This mapping implies a particular path for $z_{t}$, the subjective house price forecast error. In equilibrium, $z_{t}$ will be a function of the states and the shocks of the model, while under $\mathscr{P}$ it is perceived as an unforecastable exogenous disturbance. It is precisely in this way that $\mathscr{P}$ violates the rational expectations hypothesis.

Agents endowed with conditionally model-consistent expectations may not know the equilibrium pricing function, but they make the smallest possible expectational errors

\footnotetext{
${ }^{6}$ In order for asset market equilibrium to not enter beliefs, Walras' law requires that at least two market clearing conditions be absent from agents' information set. Consequently, in definition 2 we impose that allocations under conditionally model-consistent beliefs do not clear the goods market. In Appendix B we discuss alternatives to this assumptions.
} 
consistent with their subjective view about the evolution of stock prices. This way of setting up expectations is very tractable and can be readily applied in a variety of models, as we have shown in previous papers (Caines, 2016; Winkler, 2016). It also allows us to transparently solve the linearized version of the model.

\section{Linearized equilibrium}

The analysis in this paper will focus entirely on the linearized version of the model. The conditionally model-consistent expectations under learning imply that the learning equilibrium can be linearized in much the same way as its rational expectations counterpart.

\subsection{Rational expectations equilibrium}

Under rational expectations, we can linearize around the non-stochastic steady state to obtain:

$$
\begin{aligned}
y_{t} & =a_{t}+\alpha n_{t} \\
w_{t} & =m_{t}+a_{t}-(1-\alpha) n_{t} \\
\pi_{t} & =\beta \mathbb{E}_{t} \pi_{t+1}+\frac{(1-\xi)(1-\beta \xi)}{\xi} m_{t}+\eta_{t} \\
w_{t} & =\gamma y_{t}+\phi n_{t} \\
i_{t} & =\gamma\left(\mathbb{E}_{t} y_{t+1}-y_{t}\right)+\mathbb{E}_{t} \pi_{t+1} \\
q_{t} & =\gamma y_{t}-\beta \gamma \mathbb{E}_{t} y_{t+1}+\beta \mathbb{E}_{t} q_{t+1} .
\end{aligned}
$$

Here, lower-case variables denote log-linearizations around the zero-inflation steady state, except for $i_{t}$ which is the difference of the nominal interest rate from its steadystate level, and $\eta_{t}=\frac{(1-\xi)(1-\beta \xi)}{\xi}\left(\bar{\tau}-\tau_{t}\right)$ is the cost-push shock process. The model is simply the textbook New-Keynesian model with an extra equation for the asset price $q_{t}$. Note that it still has to be closed with an equation describing the conduct of monetary policy, such as an interest rate rule.

An important special case of the model obtains when prices are fully flexible and there are no cost-push shocks ( $\xi=0$ and $\eta_{t}=0$ ). In this case, the allocation in the rational expectations equilibrium is first-best efficient everywhere. Output and the real interest 
rate are independent of the conduct of monetary policy and are given by:

$$
\begin{aligned}
y_{t}^{n, R E} & =\frac{\phi+1}{\phi+1-\alpha(1-\gamma)} a_{t} \\
r_{t}^{n, R E} & =-\frac{\gamma(\phi+1)}{\phi+1-\alpha(1-\gamma)}\left(1-\rho_{a}\right) a_{t} .
\end{aligned}
$$

These quantities are also called the natural level of output and the natural real rate, respectively.

As is well known, the equilibrium with sticky prices can be expressed in terms of the deviation from this efficient equilibrium. To this end, denote the output gap by $\hat{y}_{t}=$ $y_{t}-y_{t}^{n, R E}$. The sticky price equilibrium can be summarized with the standard two equations:

$$
\begin{aligned}
\pi_{t} & =\beta \mathbb{E}_{t} \pi_{t+1}+\kappa \hat{y}_{t}+\eta_{t} \\
\mathbb{E}_{t} \hat{y}_{t+1}-\hat{y}_{t} & =\frac{1}{\gamma}\left(i_{t}-\mathbb{E}_{t} \pi_{t+1}-r_{t}^{n, R E}\right) .
\end{aligned}
$$

where $\kappa=(1-\xi)(1-\beta \xi)(1+\phi-\alpha+\alpha \gamma) / \xi \alpha$. These equations are the standard NewKeynesian Phillips curve and the IS equation.

\subsection{Learning equilibrium}

In order to solve the learning equilibrium, we have to proceed in two steps. The first is to solve for the agents' policy functions given their beliefs $\mathscr{P}$; the second is to impose market clearing in the asset market to back out the equilibrium asset price.

It is easy to verify that the equilibrium under learning has the same non-stochastic steady state as the rational expectations equilibrium, and we take this as our linearization point. The expectations of agents as well as their optimal choices under the subjective measure $\mathscr{P}$ are expressed as the solution to a "perceived law of motion" (PLM) 
that, in its linearized form, consists of the following equations:

$$
\begin{aligned}
y_{t} & =a_{t}+\alpha n_{t} \\
w_{t} & =m_{t}+a_{t}-(1-\alpha) n_{t} \\
\pi_{t} & =\beta \mathbb{E}_{t}^{\mathscr{P}} \pi_{t+1}+\frac{(1-\xi)(1-\beta \xi)}{\xi} m_{t}+\eta_{t} \\
w_{t} & =\gamma c_{t}+\phi n_{t} \\
i_{t} & =\gamma\left(\mathbb{E}_{t}^{\mathscr{P}} c_{t+1}-c_{t}\right)+\mathbb{E}_{t}^{\mathscr{P}} \pi_{t+1} \\
q_{t} & =\gamma c_{t}-(1-\beta) \theta h_{t}-\beta \gamma \mathbb{E}_{t}^{\mathscr{P}} c_{t+1}+\beta \mathbb{E}_{t}^{\mathscr{P}} q_{t+1} \\
c_{t} & =y_{t}-\frac{\bar{Q} \bar{H}}{\bar{Y}}\left(h_{t}-h_{t-1}\right) \\
q_{t} & =q_{t-1}+\hat{\mu}_{t-1}+z_{t} \\
\hat{\mu}_{t} & =\rho_{\mu} \hat{\mu}_{t-1}+g z_{t}
\end{aligned}
$$

This system can be solved as if it were a rational expectations model. However, under $\mathscr{P}$, there is an additional shock, the asset price forecast error $z_{t}$, that is absent under rational expectations. This shock will be predictable in equilibrium, but under under $\mathscr{P}$ agents believe it to be unforecastable. The first stage of the solution has to take this into account. Just as under rational expectations, one still needs to add an equation describing the conduct of monetary policy, such as an interest rate rule, for the above system to be fully determined.

Having solved for expectations and optimal choices given subjective beliefs $\mathscr{P}$, we now compute the equilibrium under learning (also called "actual law of motion" or ALM). To avoid confusion, we will denote with asterisks the equilibrium stochastic processes under the ALM. The equilibrium by imposing market clearing in the market for housing:

$$
h_{t}^{*}=0
$$

This equation implicitly defines the equilibrium realizations $q_{t}^{*}$ of the asset price $q_{t}$ as well as all other equilibrium outcomes.

\subsubsection{Flexible prices}

We first describe the flexible price equilibrium $\left(\xi=0\right.$ and $\left.\eta_{t}=0\right)$. We find the flexprice PLM by solving (15)-(23) under subjective beliefs $\mathscr{P}$. The learning model has two additional state variables compared to its rational expectations counterpart, $q_{t}$ and $\hat{\mu}_{t-1}$. We guess and verify that the asset demand function has the following form: 


$$
h_{t}^{n}=k_{a} a_{t}+k_{h} h_{t-1}^{n}-k_{q} q_{t}+k_{\mu} \hat{\mu}_{t-1}
$$

where the coefficients satisfy $k_{h} \in(0,1), k_{a}, k_{q}, k_{\mu}>0$. Exact expressions are in the appendix. Asset demand under learning is increasing in productivity, decreasing in the asset price, and increasing in expectations of future asset price growth.

We can also solve for the values of output and the real interest rate under flexible prices. Under subjective expectations, these are functions of the fundamental, last period's asset holdings, the asset price which is perceived as exogenous, and price growth expectations. Below, we write output and the real rate in deviation from their rational expectations counterpart: ${ }^{7}$

$$
\begin{aligned}
y_{t}^{n} & =y_{t}^{n, R E}+\frac{\alpha \gamma \kappa_{1}}{1+\phi-\alpha}\left(k_{a} a_{t}-\left(1-k_{h}\right) h_{t-1}^{n}-k_{q} q_{t}+k_{\mu} \hat{\mu}_{t-1}\right) \\
r_{t}^{n} & =r_{t}^{n, R E}+\gamma \kappa_{1}\left(k_{a}\left(2-\rho_{a}-k_{h}\right) a_{t}-\left(1-\kappa_{h}\right)^{2} h_{t-1}^{n}-k_{q}\left(1-k_{h}\right) q_{t}\right) \\
& +\gamma \kappa_{1}\left(\left(2-\rho_{\mu}-k_{h}\right) k_{\mu}+k_{q}\right) \hat{\mu}_{t-1} .
\end{aligned}
$$

where the constant $\kappa_{1}$ is

$$
\kappa_{1}=\frac{1+\phi-\alpha}{1+\phi-\alpha(1-\gamma)} \frac{\bar{Q} \bar{H}}{\bar{Y}}>0 .
$$

This natural rate is increasing in the price growth belief $\hat{\mu}_{t-1}$. Agents' subjective expectations about output under flexible prices are affected by the choice of asset holdings (which are not constant in agents' minds). An increase in expected asset price growth will increase asset demand, and households will increase their labor supply in order to finance their purchase of the asset, thereby increasing the level of output.

The natural real rate under subjective expectations can be understood by the arbitrage relationship between the return on the durable asset and the return on bonds. Combining the two asset pricing equations (19) and (20), we obtain:

$$
r_{t}^{n}=\frac{1-\beta}{\beta}\left(\gamma c_{t}-\theta h_{t}-q_{t}\right)+\mathbb{E}_{t}^{\mathscr{P}} q_{t+1}-q_{t}
$$

The expected return on the two assets has to be equal up to first order. An increase in expected durable asset price growth $\hat{\mu}_{t-1}=\mathbb{E}_{t}^{\mathscr{P}} q_{t+1}-q_{t}$ increases the expected return to the durable asset, and the real interest rate on bonds therefore has to rise as well.

\footnotetext{
${ }^{7}$ Since the PLM includes asset holdings $h_{t}$ as an endogenous state variable, there are two possible definitions of a natural real rate and natural level of output (Neiss and Nelson, 2003; Woodford, 2003). One can either define them as conditional on the actual level of asset holdings $h_{t-1}$ under sticky prices, or as conditional on the level of asset prices $h_{t-1}^{n, P L M}$ that would obtain had prices been flexible in the past as well, given the history of exogenous shocks. Here, we opt for the latter definition.
} 
To find the flex-price equilibrium under learning, i.e. the actual law of motion, one has to impose $h_{t}^{*}=0$. From the housing demand function (24), one can then immediately solve for the equilibrium asset price and the realization of the subjective forecast error:

$$
\begin{aligned}
0 & =k_{a} a_{t}-k_{q} q_{t}^{*}+k_{\mu} \hat{\mu}_{t-1}^{*} \\
\Leftrightarrow q_{t}^{*} & =\frac{k_{a} a_{t}+k_{\mu} \hat{\mu}_{t-1}^{*}}{k_{q}} .
\end{aligned}
$$

That is, the equilibrium asset price is increasing in both productivity and house price growth expectations. This is intuitive. The demand function (24) is downward-sloping, and so an increase in demand due to either higher productivity (i.e. higher income) or higher expected capital gains has to be met with an increase in the price to bring about equilibrium in the asset market.

It becomes clear that equilibrium realizations of the subjective forecast error $z_{t}$ are everything but unforecastable:

$$
z_{t}^{*}=\frac{1}{k_{q}} k_{a} a_{t}+\left(\frac{k_{\mu}}{k_{q}}-1\right) \hat{\mu}_{t-1}^{*}-q_{t-1}^{*} .
$$

This is precisely the way in which rational expectations break: If agents had the correct belief about $z_{t}$, then owing to their conditionally-model consistent expectations, their beliefs would be correct and their expectations would be rational.

Substituting the equilibrium price (27) into Equations (25) and (26), we obtain the realized level of output and the real rate under flexible prices:

$$
\begin{aligned}
& y_{t}^{n *}=y_{t}^{n, R E} \\
& r_{t}^{n *}=r_{t}^{n, R E}+\gamma \kappa_{1}\left(\left(1-\rho_{a}\right) k_{a} a_{t}+\left(\left(1-\rho_{\mu}\right) k_{\mu}+k_{q}\right) \hat{\mu}_{t-1}^{*}\right) .
\end{aligned}
$$

Under learning and flexible prices, the equilibrium level of output is the same as under rational expectations. This coincidence arises because, under flexible prices, output is determined entirely by intratemporal conditions that are independent of expectations. Nonetheless, the real interest rate does depend on expectations, and its natural level under learning is therefore different from rational expectations. In particular, it is increasing in subjectively expected asset price price growth.

\subsubsection{Sticky prices}

Under sticky prices, the PLM can be expressed in deviation from the flexible price allocation, which greatly helps our analysis. We will use tildes to denote "perceived" gaps, 
i.e. $\tilde{h}_{t}=h_{t}-h_{t}^{n, P L M}$ denotes the difference of asset holdings from their flex-price level under $\mathscr{P}$. The sticky price PLM can be summarized with three equations:

$$
\begin{aligned}
& \pi_{t}=\beta \mathbb{E}_{t}^{\mathscr{P}} \pi_{t+1}+\kappa\left(\tilde{c}_{t}+\kappa_{1} \Delta \tilde{h}_{t}\right)+\eta_{t} \\
& \tilde{c}_{t}=\mathbb{E}_{t}^{\mathscr{P}} \tilde{c}_{t+1}-\frac{1}{\gamma}\left(i_{t}-\mathbb{E}_{t}^{\mathscr{P}} \pi_{t+1}-r_{t}^{n}\right) \\
& \tilde{h}_{t}=\frac{\gamma}{\theta(1-\beta)}\left(\tilde{c}_{t}-\beta \mathbb{E}_{t}^{\mathscr{P}} \tilde{c}_{t+1}\right)
\end{aligned}
$$

The first equation is the familiar Phillips curve, but where the output gap is replaced by a consumption gap, augmented by an investment gap $\Delta \tilde{h}_{t}{ }^{8}$ The intuition is that asset purchases are financed by an increase in labor supply, which drives down firms' marginal cost of production and therefore reduces inflation. The second equation is the familar IS equation, where again the output gap is replaced by the consumption gap since the two are not equal under agents' subjective expectations. The third equation is the Euler equation for housing demand, rewritten in gap form.

Notice that the asset price $q_{t}$ itself does not appear in its own Euler equation when it is written in terms of gaps, because agents perceive $q_{t}$ as an exogenous process, independent of the degree of price stickiness. The asset price still implicitly enters equation (32) through the natural rate $r_{t}^{n}$.

To find the actual law of motion under sticky prices, one imposes $h_{t}^{*}=h_{t}^{n *}+\tilde{h}_{t}^{*}=0$ and solves for $q_{t}^{*}$. As under rational expectations, the equilibrium depends crucially on the behavior of the nominal interest rate $i_{t}$, which we have not specified yet.

\subsection{Numerical illustration}

We illustrate the properties of the learning model using a simple calibration in which we interpret the durable asset as housing. We set the labor share in output equal to $\alpha=$ 0.7 and the discount factor $\beta$ equal to 0.995 . The coefficient of relative risk aversion is set to $\gamma=1.39$ (Gandelman and Hernández-Murillo, 2014) and the inverse Frisch elasticity of labor supply is set to $\phi=0.33$. The utility scaling parameter $\chi$ is set to 0.01005 in order to achieve a steady state ratio of asset wealth to output of $Q H / Y=2.01$, which corresponds to the US ratio of real estate holdings over GDP in 2016. The parameter governing the price elasticity of demand for consumption varieties is set to $\sigma=6$ as in Christiano et al. (2010), while price stickiness is set to the standard value $\kappa=0.75$.

\footnotetext{
${ }^{8}$ Even though in equilibrium (in the ALM) there can be no housing purchases as the supply of housing is fixed, one cannot simply set $\Delta h_{t}=0$ to compute the equilibrium, since agents are not aware of this restriction.
} 
We follow Billi (2017) and set the autocorrelation of both the technology and costpush shocks to 0.8 . Finally, we calibrate the remaining four parameters $\left(\sigma_{A}, \sigma_{\tau}, \theta, g\right)$ to jointly match the volatilities of output growth $\sigma\left(\Delta Y_{t}\right)=0.64 \%$, inflation $\sigma\left(\pi_{t}\right)=0.82 \%$, house price growth $\sigma\left(\Delta Q_{t}\right)=1.51 \%$ and real wage growth $\sigma\left(\Delta w_{t}\right)=0.10 \%$. The resulting parameter values are $\sigma_{A}=0.83 \%, \sigma_{p}=0.75 \%, \theta=0.0068$ and $g=0.0041$.

We first document the effect of learning under flexible prices. Here, learning has no effect on equilibrium allocations relative to rational expectations, but manifests itself only in the realized asset price and interest rate process. Figure 2 plots the response of asset prices $Q_{t}$ and the real interest rate $i_{t}$ to a technology shock $\epsilon_{A}$ under rational expectations and learning. The effect of learning on $Q_{t}$ is typical for self-referential asset price learning models. Initially, the asset price $Q_{t}$ rises on impact because higher wage wage income raises asset demand, as under rational expectations. But the initial increase now causes a subsequent revision in beliefs $\hat{\mu}_{t}$ through the learning mechanism. The household believes that the shock has some long-run impact on house price growth and responds by increasing its demand for housing above the rational expectations demand. This response drives a further increase in $Q_{t}$ in the next period and the shock continues to propagate through belief updating thereafter. At some point, expected price growth has risen so much that it outstrips realized price growth. At this point, beliefs $\hat{\mu}_{t}$ decrease, bringing about a reduction in housing demand and therefore in equilibrium house prices, so that the process eventually reverts back to steady state.

The differing response of the interest rate between the learning and rational expectations environments directly shows the effect of expected asset price growth on the natural rate of interest. Even though the impulse response of realized consumption is exactly identical under learning and rational expectations, what matters for the interest rate is expected consumption growth. Under learning, increases in expected asset price growth in the periods following the shock also increase expected consumption growth, as agents anticipate to sell some of their asset holdings in the future to profit from the capital gains. Higher expected consumption growth implies a higher real rate of interest under the PLM than under rational expectations.

Figure 3 plots the response of $Q_{t}$ and $i_{t}$ to a technology shock $\epsilon_{A}$ under learning and flexible prices for different values of the gain parameter, $g$. A larger learning gain implies that expectations of future asset price growth respond more strongly to shocks, causing larger equilibrium price fluctuations in turn. For a gain close to zero, equilibrium house prices are very close to their rational expectations counterpart. The response of the interest rate, however, remains very different from rational expectations. As the learning gain increases, the asset price as well as the interest rate become more 
Figure 2: Effect of learning under flexible prices.
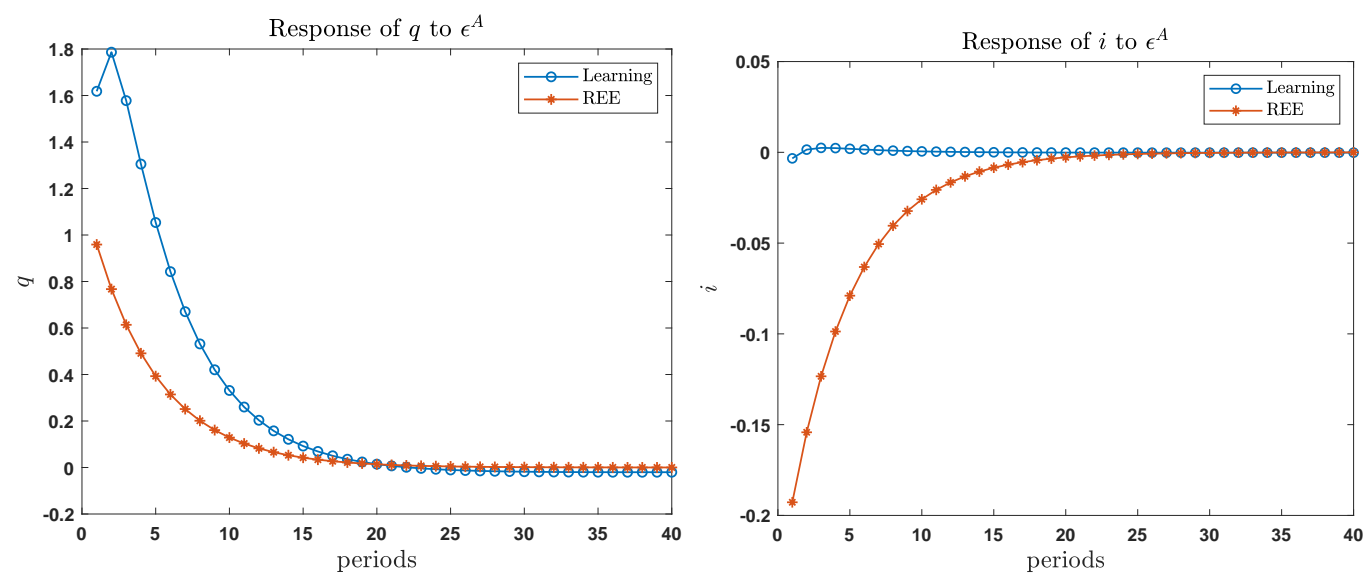

Note: Response to a one standard deviation positive technology shock $\varepsilon_{A t}$. Log percentage points. Flexible prices and zero inflation.

volatile.

Figure 3: Role of the learning gain $g$, flexible prices.
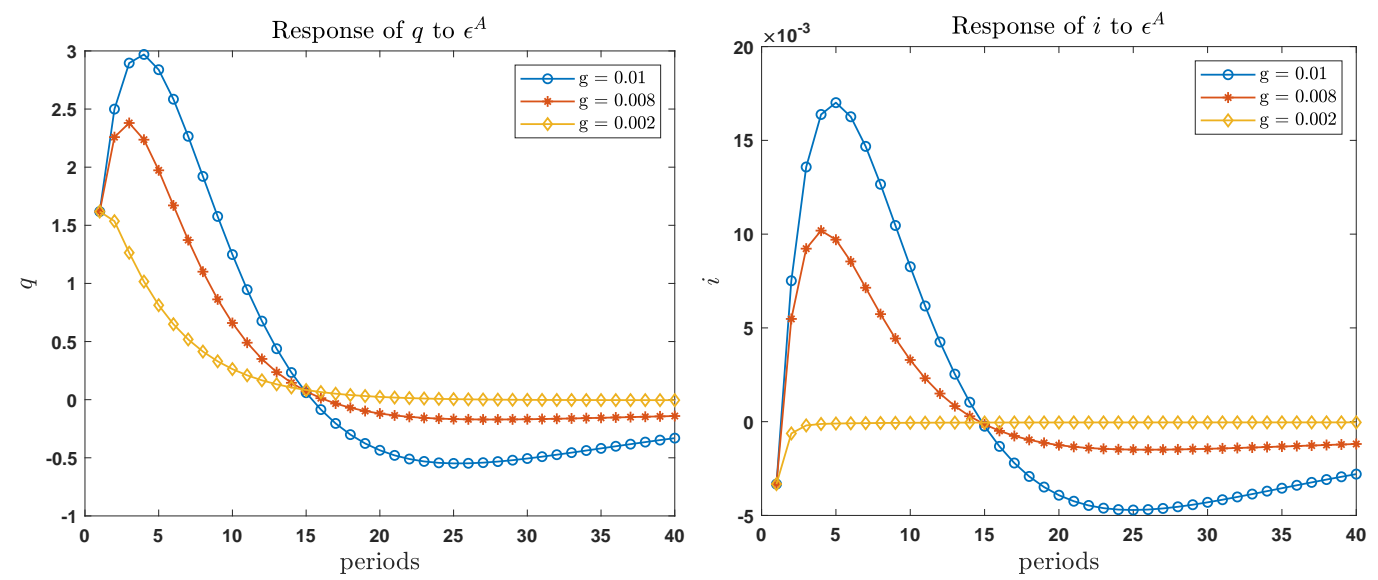

Note: Response to a one standard deviation positive technology shock $\varepsilon_{A t}$. Log percentage points. Flexible prices and zero inflation.

\section{Optimal Policy}

\subsection{Welfare function}

We provide second-order approximations to the expected discounted sum of utility in our model. Under learning, an important distinction has to be made whether welfare is evaluated under the subjective law of motion (in which asset supply is variable and prices are a random walk) or under the actual law of motion (in which asset supply is fixed and prices are functions of the model fundamentals). 
If we evaluate welfare under the actual law of motion, then welfare can be approximated by $-\sum_{t=0}^{\infty} \mathbb{E}_{0} \mathscr{L}_{t}$ up to second order, terms independent of policy, and a multiplying positive constant. The period loss function is given by

$$
\mathscr{L}_{t}=\lambda\left(\pi_{t}^{*}\right)^{2}+\hat{y}_{t}^{2}
$$

where $\lambda=2 \sigma / \kappa$ and $\hat{y}_{t}=y_{t}^{*}-y_{t}^{n, R E}$ is the deviation of equilibrium (ALM) output from its flex-price level. This loss function is identical to that of the standard rational expectations New Keynesian model. It penalizes deviations of inflation from zero as well as deviations of output from its natural level under rational expectations (11). This natural level of output is first-best efficient under the ALM.

By contrast, the welfare function under the PLM takes a quite different form. Welfare is approximated by $-\sum_{t=0}^{\infty} \beta^{t} \mathbb{E}_{0}^{\mathscr{P}} \mathscr{M}_{t}$, where the period loss function is given by

$$
\begin{aligned}
\mathscr{M}_{t} & =\lambda \pi_{t}^{2}+\tilde{c}_{t}^{2} \\
& +\frac{1-\alpha+\phi}{1+\phi-\alpha(1-\gamma)}\left(\frac{\bar{Q} \bar{H}}{\bar{Y}} \Delta \tilde{h}_{t}\right)^{2}+2 \tilde{c}_{t}\left(\frac{\bar{Q} \bar{H}}{\bar{Y}} \Delta \tilde{h}_{t}\right) \\
& -\frac{(1-\beta) \theta \alpha}{1+\phi-\alpha(1-\gamma)} \frac{\bar{Q} \bar{H}}{\bar{Y}} \tilde{h}_{t}^{2} .
\end{aligned}
$$

where $\tilde{c}_{t}$ and $\tilde{h}_{t}$ are the deviations of consumption and asset holdings from their PLMflexible price levels. Here, the period loss takes the form of deviations from the flexible price allocations under the PLM, and also includes terms for asset holdings.

In what follows, we will assume that the policymaker maximizes welfare under the actual law of motion, applying the loss function $\mathscr{L}_{t}$. Such a paternalistic objective does not imply that the central bank has superior knowledge of the economy, but merely that it has a different view of the economy than the private sector.

\subsection{Optimal policy without cost-push shocks}

We now solve for the optimal monetary policy, first under the assumption that there are no cost-push shocks. For exposition, we start by reviewing the optimal policy under rational expectations. As the flexible price equilibrium under rational expectations is first-best efficient, monetary policy is optimal if it manages to replicate the flexible price allocation in the presence of nominal rigidities. This amounts to closing the output gap and completely stabilizing inflation at the same time, as can be seen from the loss function (33). Without cost-push shocks, the "divine coincidence" holds and 
complete stabilization is achievable. The optimal policy implements

$$
\pi_{t}=0
$$

From the Phillips curve (13), it immediately follows that $\hat{y}_{t}=0$. The optimal policy can be implemented with the following rule:

$$
i_{t}=r_{t}^{n, R E}+\phi_{\pi} \pi_{t}
$$

where $\phi_{\pi}$ can be any number satisfying the Taylor principle $\phi_{\pi}>1$. The interest rate has to track the natural real rate and react more than one-for-one to inflation, i.e. satisfy the Taylor principle.

Under learning, the question is which welfare criterion to use. Should the central bank aim to maximize agents' subjectively expected discounted utility and minimize the loss function 34 under the PLM? Or should it aim to maximize average realized utility and minimize the loss function 33 under the ALM? Fortunately, both welfare criteria prescribe the same optimal outcome here.

Proposition 1. It is optimal for monetary policy under learning to implement $\pi_{t}=0$ and $y_{t}=y_{t}^{n, R E}$, regardless of whether welfare is evaluated under the ALM or the PLM. The optimal policy can be implemented with the rule $i_{t}=r_{t}^{n, P L M}+\phi_{\pi} \pi_{t}$, where $\phi_{\pi}>1$.

Proof. Suppose that the central bank implemented $\pi_{t}=0$. The PLM Phillips curve (30) then reduces to the relationship

$$
\tilde{y}_{t}=\frac{\gamma \alpha}{1+\phi-\alpha(1-\gamma)} \frac{\bar{Q} \bar{H}}{\bar{Y}} \Delta \tilde{h}_{t}
$$

Substituting into the housing demand equation (32), we obtain a second-order difference equation of the form

$$
(1-\beta) \frac{\theta}{\gamma} \tilde{h}_{t}=-\kappa_{1}\left(\Delta \tilde{h}_{t}-\beta \mathbb{E}_{t}^{\mathscr{P}} \Delta \tilde{h}_{t+1}\right)
$$

It is easily verified that the only solution to this equation is $\tilde{h}_{t}=0$. But this implies that we implement the flexible price allocation. From the subjective perspective of agents, the flexible price allocation is first-best efficient, and $\mathscr{L}_{t}=0$. Moreover, the actual equilibrium in this economy has $\pi_{t}^{*}=\pi_{t}=0$ and $y_{t}^{*}=y_{t}^{n, R E}$, as was shown in the last section. This allocation is also first-best efficient under model-consistent expectations. 
It might seem at first that the presence of learning does not alter the prescriptions of optimal policy because the target criterion strict inflation targeting is unchanged. But the implementation of this target requires a different reaction function under learning. The nominal interest rate has to track the natural real interest rate $r_{t}^{n}$ as agents perceive it under subjective expectations. This natural rate is very different from the one under rational expectations. Whereas $r_{t}^{n, R E}$ is a function of productivity $a_{t}$ only, $r_{t}^{n}$ depends additionally on beliefs $\hat{\mu}_{t}$, prices $q_{t}$ and the asset holdings $h_{t-1}$. In particular, the real rate rises when expected asset price growth $\hat{\mu}_{t}$ increases. In equilibrium, the asset price $q_{t}$ depend positively on expected price growth, and it is in this sense that the optimal monetary policy leans against the wind: In times of high prices, the interest rate has to be high to track the perceived natural real rate.

The equilibrium realization of the nominal rate under the optimal policy is the expression $r_{t}^{n *}$ derived in (29). However, an instrument rule that prescribes $i_{t}=r_{t}^{n *}+\phi_{\pi} \pi_{t}$ would fail to implement the optimal policy. The equilibrium natural rate $r_{t}^{n *}$ only coincides with $r_{t}^{n}$ when $h_{t}=0$. While this must be the case in equilibrium, agents under $\mathscr{P}$ contemplate other possible realizations of the house price for which they plan on choosing $h_{t} \neq 0$. These off-equilibrium states of the world enter into agents' expectations of future marginal costs. Therefore, the central bank must promise to stabilize inflation even in these off-equilibrium states. Tracking only the equilibrium natural rate is insufficient: It must track the perceived natural rate.

As an illustration, Figure 4 shows impulse responses for the learning model with three interest rate equations:

$$
\begin{aligned}
i_{t} & =r_{t}^{n}+1.05 \pi_{t} \\
i_{t} & =r_{t}^{n *}+1.05 \pi_{t} \\
i_{t} & =r_{s s}+1.5 \pi_{t}+0.125 \hat{y}_{t} .
\end{aligned}
$$

The first equation (35) implements strict inflation targeting as per Proposition 1. The only difference of the second equation (36) is that the monetary authority reacts to the equilibrium process of the natural rate instead of the perceived process. Figure 4 shows how using the ALM natural rate of interest in the the policy rule does not yield a zero inflation outcome. As discussed in the last section, the central bank must promise to stabilize inflation even in those states that are never reached in equilibrium-that is, when the housing market doesn't clear-but contemplated by agents under their subjective expectations. Using the ALM natural rate in the policy rule fails to do so. Due do their beliefs about the process governing $Q_{t}$, agents under the PLM do not account for the effect of the technology shock on future asset price growth. Consequently, the 
initial response of consumption is smaller than under rational expectations. From the standpoint of an agent under the flex price ALM on the other hand, the technology shock has an anticipated positive impact on the path of $Q_{t}$ due to expected asset demand. As a result, the initial consumption response and subsequent consumption decline will be greater. The ALM natural rate of interest declines more upon the impact of the shock than does the PLM natural rate of interest. When a monetary authority uses the ALM natural rate in its policy rule as in (36), then, the nominal interest does not increase sufficiently to prevent an inflationary response.

Figure 4: Optimal policy and alternatives after a technology shock.
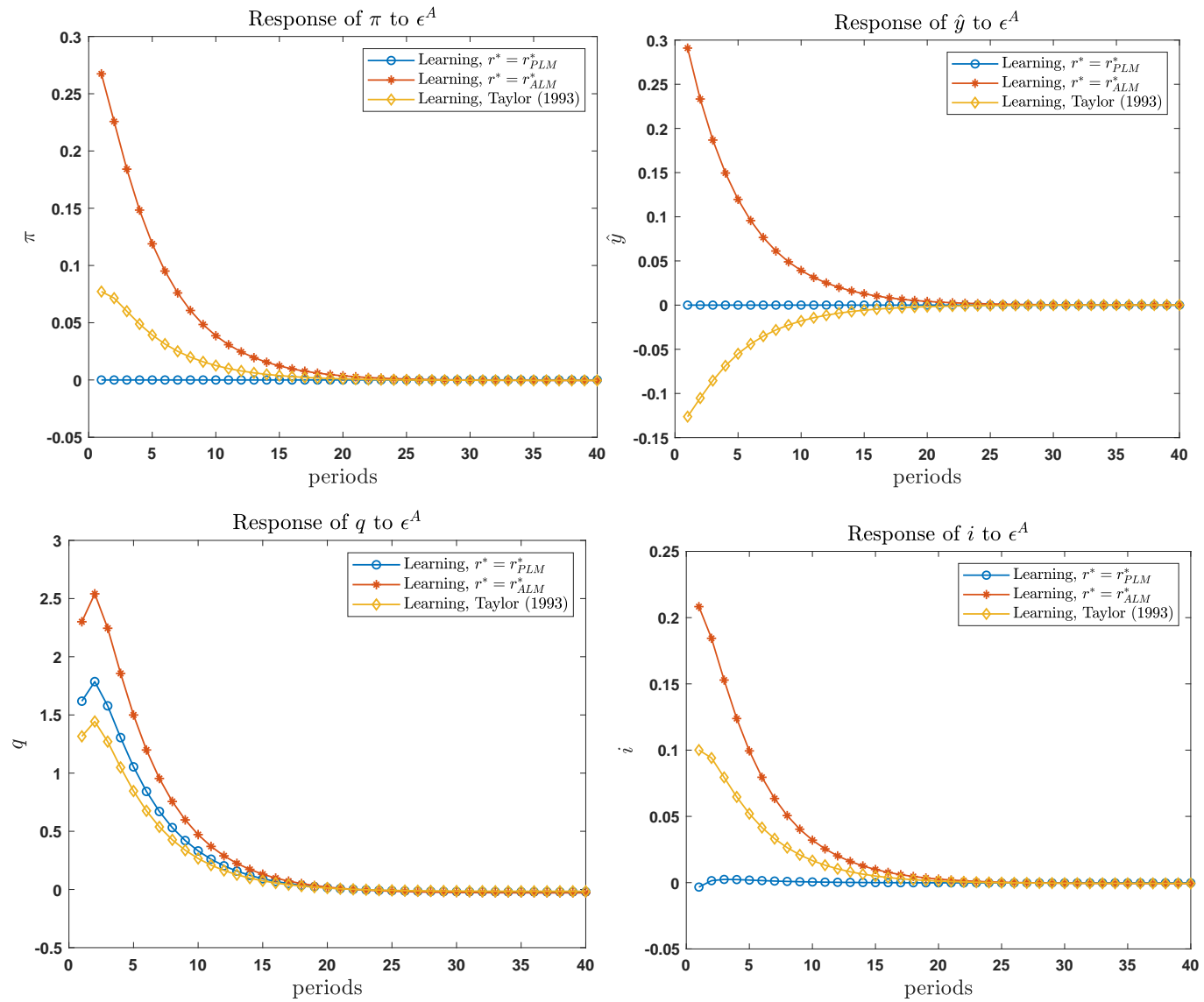

Note: Response to a unit standard deviation positive technology shock $\varepsilon_{A t}$ under sticky prices. Log percentage points. The interest rate rules used are given in Equations (35)-(37).

Finally, the third equation is a standard Taylor rule. Figure 4 shows that this rule performs somewhat better in terms of outcomes, but is still far from the optimal policy. It is worth notint that the nominal interest rate is more volatile under the Taylor rule than under the optimal rule (35), which reacts to asset prices. The reason is of course that the stabilization benefits of reacting to asset prices make equilibrium nominal rates more stable as well. 


\subsection{Optimal policy with cost-push shocks}

The presence of cost-push shocks breaks the so-called "divine coincidence" under rational expectations, so that the first-best allocation is not feasible. Here, we will show first that in principle, a sophisticated policymaker with knowledge of the precise nature of the belief distortions under learning can restore the first-best outcome by twisting private sector expectations to its advantage through a highly non-linear policy. This is clearly the optimal policy, but we do not see it as relevant in practice. Instead, we restrict the set of admissible policies to a known class of linear targeting rules and show that it is possible to replicate the allocations of the RE-optimal policy under discretion and commitment. As in the case without cost-push shocks, implementing these policies requires the nominal interest rate to track the natural rate of interest under the PLM, which is increasing in asset price expectations.

Proposition 2. With cost-push shocks and learning, it is possible to implement the firstbest allocation with the targeting rule $\pi_{t}=-\left(\beta \rho_{\eta}\right)^{-1} \eta_{t}+b_{t} z_{t}$, where $b_{t}$ is a non-linear state-dependent coefficient.

Proof. See the appendix.

Clearly, this is the optimal policy with cost-push shocks, but this policy implies a high degree of belief manipulation by the central bank that is particularly vulnerable to the Lucas critique. ${ }^{9}$ The policy relies on a promise of particular outcomes of inflation in states that are never realized in equilibrium, and it is difficult to see how agents would come to believe the credibility of such a policy in the first place. The non-linear nature of the policy also adds to its limitations.

In order to limit the amount of manipulation the central bank can exert on private sector beliefs, we now restrict the set of admissible policies to a class that does not rely on a systematic exploitation of agents' systematic forecast errors. We require that the target criterion for inflation be a process that is the same for both the probability measure of agents' expectations and that of the equilibrium (i.e. $\pi_{t}^{*}=\pi_{t}$ ). This class is large enough to include the optimal target criteria (both under commitment and discretion) for the case in which agents have rational expectations. The target criterion can also be made contingent on equilibrium asset price realizations. But we do rule

\footnotetext{
${ }^{9}$ This problem was anticipated by Woodford (2010) who speculated that one "might even conclude that the optimal policy under learning achieves an outcome better than any possible rationalexpectations equilibrium, by inducing systematic forecasting errors of a kind that happen to serve the central bank's stabilization objectives".
} 
out target criteria that make inflation contingent on asset price realizations that are contemplated by agents, but never realized in equilibrium.

Within this class, optimal policy is identical to its rational expectations counterpart in terms of the target criterion, but not in terms of the implementation:

Proposition 3. Consider the class of policies for which $\left(\pi_{t}\right)_{t=0}^{\infty}$ is $u_{t}$-measurable; that $i s, \pi_{t}$ depends only on the fundamental shocks $u_{t}$ but not on the perceived asset price forecast errors $z_{t}$. Within this class:

1. The optimal target criterion under commitment (from the timeless perspective) is given by $\zeta p_{t}=-\Delta m_{t}$ for some $\zeta>0$, where $p_{t}$ is the price level. The optimal commitment policy achieves the same equilibrium allocation as the commitment solution under rational expectations.

2. Similarly, the optimal target criterion under discretion is given by $\zeta \pi_{t}=-m_{t}$. The optimal discretionary policy achieves the same equilibrium allocation as the discretionary solution under rational expectations.

3. In both cases above, optimal policy can be implemented with an interest rule of the form $i_{t}=r_{t}^{n}+A(L) \eta_{t}+\phi_{\pi} \pi_{t}$, where $A(L) \eta_{t}$ is a lag polynomial in the cost-push shock $\eta_{t}$ and $\phi_{\pi}>1$.

Proof. See the appendix.

Flexible inflation targeting remains optimal under learning. But the expression for the nominal interest rate shows that the equilibrium interest rate path depends on the perceived natural rate, which is increasing in the level of asset prices as well as the subjective expectation of future asset price growth. Therefore, the optimal nominal interest rate effectively reacts positively to asset prices.

\section{Simple rules}

Implementing optimal policy in the learning environment requires knowledge of the natural rate of interest under the PLM. In particular, it implies that the monetary authority knows the agents' beliefs about $\mu_{t}$, which in part determine $r_{t}^{n}$ in equilibrium. An obvious concern is that beliefs that are subjective and privately held are hard to measure. In this section, we show that incorporating a positive reaction to asset prices into a standard interest rate rule can allow a monetary authority who does not observe 
beliefs to approximate optimal policy under learning. This result is not a natural consequence of the optimal policy analysis, because simple rules can be quite far from the optimal policy. A reaction to asset prices will tend to be beneficial in a rule if periods of elevated asset prices coincide with excess aggregate demand under that particular rule. For our calibrated model and the standard Taylor rule, that turns out to be the case.

We re-compute the model under the assumption that the monetary authority is following a Taylor-type rule of the form:

$$
i_{t}=\rho_{i} i_{t-1}+\left(1-\rho_{i}\right) \cdot\left(r_{s s}+\phi_{\pi} \cdot \pi_{t}+\phi_{y} \cdot \hat{y}_{t}+\phi_{q} \cdot \sum_{s=0}^{\infty} \omega^{s} \Delta \log Q_{t-s}\right)
$$

The rule depends on inflation and the output gap, and has an additional term for asset prices: a moving average of past price changes, with a weight on past observations that decays at the rate $\tilde{\omega} \in(0,1)$. In what follows, we keep the coefficient on inflation at $\phi_{\pi}=1.5$ and find the tuples $\left(\rho_{i}, \phi_{y}, \phi_{q}, \tilde{\omega}\right)$ that minimize either (33) under the equilibrium probability measure, or (34) under the subjective probability measure. ${ }^{10} \mathrm{We}$ impose the constraint $0 \leq \tilde{\omega} \leq 0.999$. Table 1 shows the optimized rule coefficients and compares them to the outcome of the optimal target criterion from Section 5.2.

The first three rows show results under rational expectations. Row (1) shows our baseline policy rule while Row (2) shows the optimized values of persistence and the output gap coefficient, holding constant the coefficient on inflation. This rule is more aggressive than the standard Taylor rule and leads to welfare gains from output gap stabilization. Alowing for a non-zero asset price response in the optimization leads to $\phi_{q}=0$ : There is no benefit from leaning against the wind under rational expectations. ${ }^{11}$ Row (3) also shows the outcomes from the optimal target rule derived in Section 5.2. This target rule dramatically improves welfare, mainly by reducing inflation volatility.

Under learning, the picture is quite different. Row (4) repeats the baseline policy rule, with both interest rate persistence $\rho_{i}$ and the output gap response $\phi_{y}$ set to their optimized value. The resulting rule displays zero interest rate persistence and has a less aggresive output gap response than the standard Taylor rule. Nevertheless, inflation volatility is lower than under rational expectations, thereby improving welfare. Row (5) shows the outcomes from the optimal target rule derived in 5.2. As was shown in

\footnotetext{
${ }^{10}$ If one also optimizes over the coefficient and inflation, then the optimal policy under rational expectations is given by $\phi_{\pi} \rightarrow \infty$ and $\phi_{y} / \phi_{\pi} \rightarrow \zeta>0$ (Boehm and House, 2014). The outcomes of this limit policy are also attainable under learning with a similar policy that also responds infinitely strongly to inflation and the ouput gap. In this section, we rule out infinite rule coefficients by keeping the inflation coefficient fixed, and focus only on the tradeoff of reacting to the output gap and asset prices.

${ }^{11}$ In fact, the optimal coefficient on asset prices would be slightly negative had we not imposed $\phi_{q} \geq 0$.
} 
Table 1: Performance of optimized simple rules.

\begin{tabular}{|c|c|c|c|c|c|}
\hline & Rational Expectations & $\sigma\left(\pi_{t}\right)$ & $\sigma\left(\hat{y}_{t}\right)$ & $\sigma\left(\Delta q_{t}\right)$ & $\mathscr{L}$ \\
\hline (1) & $i_{t}=r_{s s}+1.5 \pi_{t}+0.125 \cdot \hat{y}_{t}$ & 0.349 & 0.451 & 0.801 & 3.315 \\
\hline (2) & $\begin{array}{l}i_{t}=\rho_{i}^{*} i_{t-1}+\left(1-\rho_{i}^{*}\right) \cdot\left(r_{s s}+1.5 \pi_{t}+\phi_{y}^{*} \cdot \hat{y}_{t}\right) \\
\left\{\rho_{i}^{*}, \phi_{y}^{*}\right\}=\{0.844,0.331\}\end{array}$ & 0.249 & 0.472 & 0.515 & 1.888 \\
\hline \multirow[t]{2}{*}{ (3) } & $\begin{array}{c}\pi_{t}=\zeta^{*} \eta_{t} \\
\zeta^{*}=0.040\end{array}$ & 0.050 & 0.492 & 1.098 & 0.577 \\
\hline & Learning & $\sigma\left(\pi_{t}\right)$ & $\sigma\left(\hat{y}_{t}\right)$ & $\sigma\left(\Delta q_{t}\right)$ & $\mathscr{L}$ \\
\hline (4) & $\begin{array}{l}i_{t}=\rho_{i}^{*} i_{t-1}+\left(1-\rho_{i}^{*}\right) \cdot\left(r_{s s}+1.5 \pi_{t}+\phi_{y}^{*} \cdot \hat{y}_{t}\right) \\
\left\{\rho_{i}^{*}, \phi_{y}^{*}\right\}=\{0,0.041\}\end{array}$ & 0.051 & 0.476 & 1.741 & 0.559 \\
\hline (5) & $\begin{array}{c}\pi_{t}=\zeta^{*} \eta_{t} \\
\zeta^{*}=0.040\end{array}$ & 0.050 & 0.492 & 1.879 & 0.577 \\
\hline (6) & $\begin{array}{l}i_{t}=\rho_{i}^{*} i_{t-1}+\left(1-\rho_{i}^{*}\right) \cdot\left(r_{s s}+1.5 \pi_{t}\right) \\
\rho_{i}^{*}=0\end{array}$ & 0.014 & 0.541 & 1.911 & 0.656 \\
\hline (7) & $\begin{array}{l}\text { BG (1999) w/ asset price } \\
i_{t}=\rho_{i}^{*} i_{t-1}+\left(1-\rho_{i}^{*}\right) \cdot\left(r_{s s}+1.5 \pi_{t}+\phi_{q}^{*} \cdot \log q_{t-1}\right) \\
\quad\left\{\rho_{i}^{*}, \phi_{q}^{*}\right\}=\left\{0,3.6 \times 10^{-5}\right\}\end{array}$ & 0.013 & 0.541 & 1.912 & 0.656 \\
\hline (8) & $\begin{array}{l}\text { BG (2001) w/ asset price } \\
i_{t}=\rho_{i}^{*} i_{t-1}+\left(1-\rho_{i}^{*}\right) \cdot\left(r_{s s}+1.5 \pi_{t}+\phi_{q}^{*} \cdot \log q_{t}\right) \\
\quad\left\{\rho_{i}^{*}, \phi_{q}^{*}\right\}=\left\{0,7.5 \times 10^{-4}\right\}\end{array}$ & 0.012 & 0.541 & 1.911 & 0.655 \\
\hline (9) & $\begin{array}{l}i_{t}=\rho_{i}^{*} i_{t-1}+\left(1-\rho_{i}^{*}\right) \cdot\left(r_{s s}+1.5 \pi_{t}+\phi_{q}^{*} \cdot \sum_{s=0}^{\infty} \omega^{* s} \Delta \log Q_{t-s}\right) \\
\left\{\rho_{i}^{*}, \phi_{q}^{*}, \omega^{*}\right\}=\{0,0.010,0.268\}\end{array}$ & 0.025 & 0.531 & 1.792 & 0.645 \\
\hline (10) & $\begin{array}{l}\text { FM }(2007) \text { w/ asset price } \\
\quad i_{t}=\rho_{i}^{*} i_{t-1}+\left(1-\rho_{i}^{*}\right) \cdot\left(r_{s s}+1.5 \pi_{t}+\phi_{y}^{*} \cdot \hat{y}_{t}+\phi_{q}^{*} \cdot \log q_{t}\right) \\
\quad\left\{\rho_{i}^{*}, \phi_{y}^{*}, \phi_{q}^{*}\right\}=\{0.405,0.064,0.012\}\end{array}$ & 0.045 & 0.441 & 1.700 & 0.476 \\
\hline (11) & $\begin{array}{l}i_{t}=\rho_{i}^{*} i_{t-1}+\left(1-\rho_{i}^{*}\right) \cdot\left(r_{s s}+1.5 \pi_{t}+\phi_{y}^{*} \cdot \hat{y}_{t}+\phi_{q}^{*} \cdot \sum_{s=0}^{\infty} \omega^{* s} \Delta \log Q_{t-s}\right) \\
\left\{\rho_{i}^{*}, \phi_{y}^{*}, \phi_{q}^{*}, \omega^{*}\right\}=\{0.408,0.064,0.012,0.999\}\end{array}$ & 0.045 & 0.442 & 1.701 & 0.477 \\
\hline
\end{tabular}


Section 5.2, the allocations induced by this rule are identical to those in Row (3). Rows (6) - (8) show the effect of including the asset price level in a rule that does not have an output response as in Bernanke and Gertler (1999) or Bernanke and Gertler (2001). In each case the optimal asset price response is near-zero, with no gain in welfare. The situation is somewhat different when a weighted average of past asset price growth is included instead (Row (9)). The optimal asset price response is positive, with a slight decrease in output gap volatility driving a 1.7 percent gain in welfare. The gains to reacting to asset prices are more pronounced when an output gap response is included in the simple rule. Row (11) shows the results when the model is simulated under the simple rule specified in (38) with optimized coefficient values. Once again reacting to the asset price is optimal. The optimal coefficient on the output gap is positive, and the optimal $\omega$ is set very close to one. With this value its dynamics are closer to the subjective belief $\hat{\mu}_{t}$, which itself is a moving average of past price changes. The reaction to the asset price stabilizes the output gap and lowers the volatility of asset prices, resulting in a near-15 percent welfare gain. The results are similar when the asset price level is included in the rule instead of the weighted average, as in Faia and Monacelli (2007). It is important to highlight that under learning the simple interest rate rules outperform the optimal target criterion when a reaction to both asset prices and the output gap is present. It is also worth noting that the optimized interest rate rules do not reduce asset price volatility to its level under rational expectations. The reason is of course that asset price volatility does not enter the loss function directly, and so the central bank cares only about the effects of asset price movements on inflation and the output gap.

To get a better idea of the effects of monetary policy reactions to asset prices and the output gap under learning, we compute loss function values as well as the volatilities of inflation, the output gap and asset prices over a range of parameters. We fix the moving average weight to $\tilde{\omega}=0.9$, the interest rate persist to $\rho_{i}=0$, and vary the magnitude of the response coefficients $\phi_{y}$ and $\phi_{q}$ on the output gap and inflation. ${ }^{12}$ Figure 5 contains the results as surface plots.

The effect of changes in the output gap coefficient are as expected: They lower the volatility of the output gap itself, but increase the volatility of inflation. This trade-off arises because the model has cost-push shocks in it. A reaction to the output gap also lowers asset price volatility in this model.

But the asset price coefficient also plays an important role. The volatility of asset prices is decreasing in the asset price response $\phi_{q}$. The volatility of the output gap is only lit-

\footnotetext{
${ }^{12}$ Our results are qualitatively robust to changes in the moving average weight $\omega$. In particular, a positive reaction to asset prices $\phi_{q}>0$ always reduces asset price volatility.
} 
Figure 5: Loss values and volatilities for different output gap and asset price coefficients.

(a) Inflation volatility.

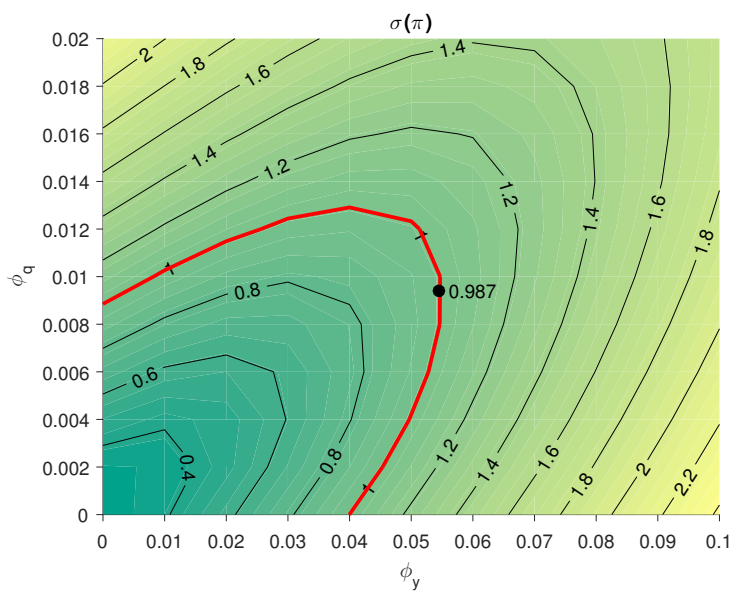

(c) Asset price volatility.

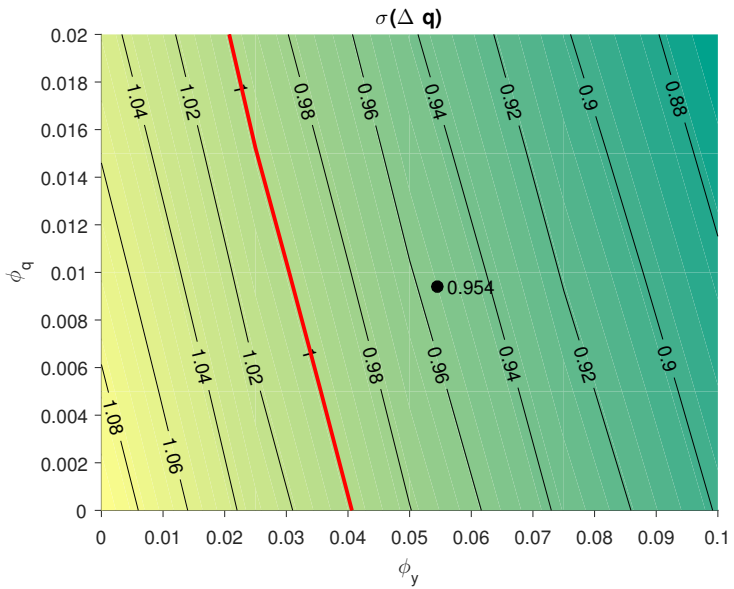

(b) Output gap volatility.

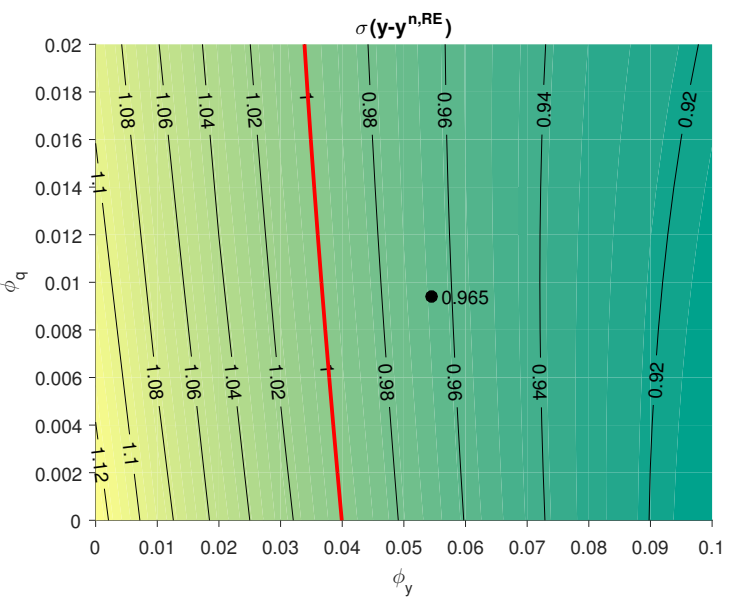

(d) Loss function.

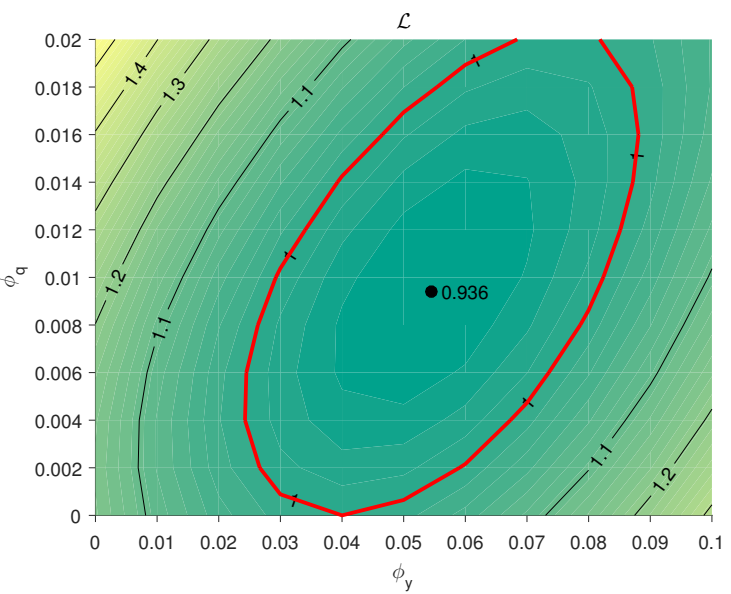

Note: Unconditional standard deviation of inflation $\pi_{t}$, house price growth $\Delta q_{t}$ and output gap $\hat{y}_{t}$ under the ALM, and loss function $\mathscr{L}$, as a function of $\phi_{y}$ and $\phi_{q}$, keeping $\tilde{\omega}=0.9$ throughout. All values are reported relative to the rule in Row (5) of Table 1. Red lines denote contour lines at unity, i.e. the value attained by the optimal coefficient $\phi_{y}$ with $\phi_{q}=0$. Black dots denote the value attained under the unrestricted optimal coefficients, reported in Row (6) of Table 1.

tle affected by the asset price response, but the volatility of inflation is reduced significantly with $\phi_{q}>0$. Therfore, the loss function is minimized at a strictly interior point at which the central bank reacts to both the output gap and asset price growth.

Importantly, a reaction to asset prices always decreases asset price volatility (regardless of the value of $\tilde{\omega})$. This is in stark contrast to the rational bubbles of Gali $(2014,2017)$. Rational bubbles grow at the rate of interest, and so raising rates when a bubble is growing makes it grow even faster, causing more volatility. By contrast, raising rates in the learning model here has the effect of lowering the house price today: A higher real rate requires a higher expected return on housing. For a given expected capital gain $\hat{\mu}_{t}$, a higher return needs to be brought about by a lower price today. The reduction in the 
house price today then reduces optimism about future price growth.

\section{Extension: General Asset Price Beliefs}

One might wonder whether our results hinge in any way on our assumption that agents' subjective beliefs about asset prices are given by a simple random walk with drift. In this section, we show that this is not the case. All our results so far extend to a very general form of beliefs about asset prices that encompass extrapolative as well as attenuating beliefs relative to rational expectations, "natural expectations" (Fuster et al., 2012), "diagnostic expectations" (Bordalo et al., 2018) and other forms of non-rational beliefs. The only assumptions we have to retain are that expectations are conditionally model-consistent in the sense of Definition 2, and that the subjective law of motion for asset prices is independent of policy. While this second assumption is admittedly somewhat limiting, an environment in which agents do think that monetary policy can curb asset price booms probably provides an even stronger rationale for reacting to asset prices than what we discuss here.

We replace the subjective law of motion for asset prices in (3)-(4) with a general belief of the form:

$$
q_{t}=A(L) z_{t}+B(L) u_{t}
$$

where $A$ and $B$ are arbitrary lag polynomials. Subjective beliefs can depend in an arbitrary way on the fundamental shocks $u_{t}$ (i.e. productivity and cost-push shocks) as well as a subjective forecast error $z_{t}$. The general formula nests rational expectations, our baseline belief system, and a multitude of other forms of subjective beliefs.

Under flexible prices, we can show that the housing demand function in the PLM (i.e. under $\mathscr{P}$ ), which previously was given by (24), is replaced by:

$$
h_{t}^{n}=k_{a} a_{t}+k_{h} h_{t-1}^{n}+k_{q} q_{t}+\tilde{k}_{\mu} \sum_{s=0}^{\infty} \tilde{\rho}^{s} \mathbb{E}_{t}^{\mathscr{P}} \Delta q_{t+s+1}
$$

The coefficients $k_{a}, k_{h}$ and $k_{q}$ are the same as in the original model, and moreover we have $\tilde{k}_{\mu}>0$ and $0<\tilde{\rho}<\beta$. The natural real rate under the PLM has a somewhat more convoluted form, but importantly, it is still increasing in expectations of asset price 
growth:

$$
\begin{aligned}
r_{t}^{n} & =r_{t}^{, R E}+\gamma \kappa_{1}\left(k_{a}\left(2-\rho_{a}-k_{h}\right) a_{t}-\left(1-\kappa_{h}\right)^{2} h_{t-1}^{n}+k_{q}\left(1-k_{h}\right) q_{t}\right) \\
& +\gamma \kappa_{1}\left(\frac{\tilde{k}_{\mu}}{\tilde{\rho}}-k_{q}\right) \mathbb{E}_{t}^{\mathscr{P}} \Delta q_{t+1}+\gamma \kappa_{1} \tilde{k}_{\mu}\left(1-k_{h}-\frac{1-\tilde{\rho}}{\tilde{\rho}}\right) \sum_{s=1}^{\infty} \tilde{\rho}^{s} \mathbb{E}_{t}^{\mathscr{P}} \Delta q_{t+s+1} .
\end{aligned}
$$

Moreover, since the asset price $q_{t}$ is independent of policy under the PLM, it drops out of the equations describing the dynamics of the sticky price equilibrium relative to flexible prices. Equations (30)-(32) continue to hold and the asset price enters only indirectly through the natural real rate $r_{t}^{n}$, which itself is independent of policy. As a consequence, all our results from Section 5 continue to hold.

\section{Extension: Asset Production}

In the model presented thus far, learning causes distortions only through wealth effects affecting aggregate demand. But one of the main concerns about financial stability in macroeconomics is that overoptimism and -pessimism in financial markets might cause inefficient investment fluctuations. Here, we extend the model to allow for the durable asset to be produced instead of being in fixed supply. In this extension, asset price misalignments do distort investment decisions in addition to aggregate demand, and therefore also distort the flexible price allocation. This fundamentally changes the monetary policy tradeoff. We show that in this case, the optimal policy target criterion under learning is no longer the same as under rational expectations. Instead, the optimal policy "leans against the wind" in the sense of Svensson (2017): The central bank should tolerate low inflation at times when current or future expected asset prices are inefficiently high.

Relative to the baseline model, we now assume that the stock of the durable asset depreciates at the rate $\delta$. The representative household owns firms that can produce $X_{t}$ durable assets from $K_{t}$ consumption goods. Their production function has decreasing returns to scale:

$$
X_{t}=A_{h} K_{t}^{\omega}
$$

Production takes place within one period. The profits of the investment firms are:

$$
\Pi_{t}=Q_{t} X_{t}-K_{t}
$$


and profit maximization leads to the first order condition:

$$
I_{t}=A_{h}\left(\omega Q_{t} A_{h}\right)^{\frac{\omega}{1-\omega}}
$$

The budget constraint of the household becomes

$$
C_{t}+Q_{t}\left(H_{t}-(1-\delta) H_{t-1}\right)+\frac{1+i_{t-1}}{1+\pi_{t}} B_{t-1}=W_{t} N_{t}+\Pi_{t}+T_{t}+B_{t}
$$

Market clearing in the durable asset market now requires

$$
H_{t}=(1-\delta) H_{t-1}+X_{t}
$$

The equilibrium is defined analogously to section 3. Agents do not know the market clearing condition (45), but instead hold subjective beliefs that the asset price follows equations (3)-(4). Beliefs about the hidden state $\mu_{t}$ are updated using the Kalman filter as before, and expectations about the remaining equilibrium objects satisfy conditional model consistency as defined in section 3.

\subsection{Linearized equilibrium}

We relegate the complete description of the linearized equilibrium to the appendix. Importantly, the natural real rate of interest in the model with asset production continues to be increasing in the asset price belief $\hat{\mu}_{t}$. As before, we can write the PLM under sticky prices in deviation from the flexible price PLM:

$$
\begin{aligned}
\pi_{t} & =\beta \mathbb{E}_{t}^{\mathscr{P}} \pi_{t+1}+\kappa\left(\tilde{c}_{t}+\kappa_{1} \tilde{x}_{t}\right)+\eta_{t} \\
i_{t} & =\gamma\left(\mathbb{E}_{t}^{\mathscr{P}} \tilde{c}_{t+1}-\tilde{c}_{t}\right)+\mathbb{E}_{t}^{\mathscr{P}} \pi_{t+1}+r_{t}^{n} \\
\theta(1-\tilde{\beta}) \tilde{h}_{t} & =\gamma \tilde{c}_{t}-\tilde{\beta} \gamma \mathbb{E}_{t}^{\mathscr{P}} \tilde{c}_{t+1} .
\end{aligned}
$$

where $\tilde{\beta}=\beta(1-\delta)$ and the constants $\kappa$ and $\kappa_{1}$ are now defined as:

$$
\begin{aligned}
\kappa & =\frac{1-\xi}{\xi} \frac{1-\beta \xi}{\alpha}\left(\frac{\bar{C}}{\bar{Y}}(1+\phi-\alpha)+\alpha \gamma\right) \\
\kappa_{1} & =\frac{1+\phi-\alpha}{\frac{\bar{C}}{\bar{Y}}(1+\phi-\alpha)+\alpha \gamma} \frac{\delta \bar{Q} \bar{H}}{\bar{Y}} .
\end{aligned}
$$




\subsection{Welfare functions}

We can derive a quadratic approximation of welfare to evaluate different policies. As before, we evaluate welfare under the actual law of motion. Welfare can be approximated (up to second order, a multiplicative constant, and terms independent of policy) by $-\sum_{t=0}^{\infty} \mathbb{E}_{0} \mathscr{L}_{t}$, where the period loss function is given by

$$
\begin{aligned}
\mathscr{L}_{t} & =2 \sigma \frac{\xi}{1-\xi} \frac{1}{1-\beta \xi}\left(\pi_{t}^{*}\right)^{2}+\gamma \frac{\bar{C}}{\bar{Y}} \hat{c}_{t}^{2}+(1-\beta(1-\delta)) \theta \frac{\bar{Q} \bar{H}}{\bar{Y}} \hat{h}_{t}^{2} \\
& +(1-\omega) \frac{\bar{Q} \bar{H}}{\bar{Y}} \delta^{2} \hat{x}_{t}^{2}+\frac{1-\alpha+\phi}{\alpha} \hat{y}_{t}^{2} .
\end{aligned}
$$

Compared to the standard New Keynesian model, we have to take into account variation in the asset stock $h_{t}$ that the household owns, as well as variations in asset investment $x_{t}$. As before, the rational expectations equilibrium under flexible prices is first-best efficient, and the loss function can therefore be written in deviations from it.

\subsection{Optimal policy}

As before, we restrict ourselves to the class of policies for which the target criterion for inflation is robust to the Lucas critique. We then find:

Proposition 4. Consider the class of policies for which $\pi_{t}$ is $u_{t}$-measurable; that is, $\pi_{t}$ depends only on the fundamental shocks $u_{t}$ but not on the perceived asset price forecast errors $z_{t}$. Within this class, the optimal commitment policy takes the form

$$
\begin{aligned}
\zeta p_{t} & =-\left(m_{t}+\chi_{t}-(1-\delta) \chi_{t-1}\right) \\
\chi_{t} & =k_{h} \chi_{t-1}+c_{0} \hat{h}_{t-1}+\sum_{s=0}^{\infty} c_{s} \mathbb{E}_{t} \hat{q}_{t+s}
\end{aligned}
$$

for some $\zeta>0$, where $p_{t}$ is the price level. If the gain parameter $g$ is sufficiently small, then the coefficients $c_{-1}$ and $\left(c_{s}\right)_{s=0}^{\infty}$ are all strictly positive.

Proof. See the appendix.

The proposition establishes that the optimal policy leans against the wind: Even when the output gap, measured here by marginal costs $m_{t}$, is closed and the inherited housing stock $h_{t-1}$ is efficient, the welfare-maximizing central bank wants to set inflation lower than its target if current or future expected asset prices are inefficiently high. Inefficiently high asset prices imply real distortions because they lead to over-investment. 
Low inflation mitigates over-investment because it induces lower output and higher real interest rates, both of which reduce asset demand.

The proposition comes with the qualification that the learning gain $g$ must be sufficiently small. For large values of $g$, we cannot ensure that the central bank always wants to lean against the wind. The reason is that large values of $g$ lead to oscillatory patterns in the response of asset prices to subjective return surprises, including those induced by monetary policy. While it will always be the case that tighter monetary policy will lead to lower asset prices and investent today, the endogenous belief dynamics of the model can lead to higher asset prices in the future, which would be counterproductive to counter over-investment. For low values of the gain $g$ though, tighter monetary policy will not increase asset prices at any future horizon.

\subsection{Numerical illustration}

We illustrate the dynamics of the model with a simple calibration. We take the same parameters as in the baseline model, and calibrate $\left\{\theta, g, \omega, \delta, \sigma_{A}, \sigma_{p}\right\}$ so as to match the volatilities of output growth, inflation, house price growth, real wage growth, residential investment, as well as the mean output share of residential investment. The resulting parameter values are $\theta=0.081, g=0.027, \omega=0.547, \delta=0.021, \sigma_{A}=0.72 \%$, and $\sigma_{p}=0.90 \%$.

Figure (6) illustrates that learning has real effects in this model with production even under flexible prices. It compares the flexible price-responses to a productivity shock under rational expectations and learning. As before, learning increases asset price volatility. But asset production now responds to asset demand, diverting resources away from consumption in an asset price boom.

As was the case with the baseline model, strict inflation targeting requires the policymaker to track movements in the natural rate of interest in the PLM; but this is no longer optimal. This is illustrated in figure 7 , which shows responses to a one standard deviation productivity shock for rules 35-37. The figure shows that when the central bank sets interest rates according to the perceived natural rate of interest $r_{t}^{n, P L M}$, it achieves strict inflation targeting as before, and therefore implements the flexible price allocation under learning. But this allocation is inefficient because of the investment decisions taken under non-rational expectations and the housing gap $\hat{h}_{t}$ is not closed. Tracking the equilibrium (ALM) process of the natural rate delivers even worse outcomes. The standard Taylor rule, by contrast, manages to keep the housing gap relatively small following a technology shock, but does not stabilize inflation and also 
Figure 6: Effect of learning under flexible prices, with asset production.
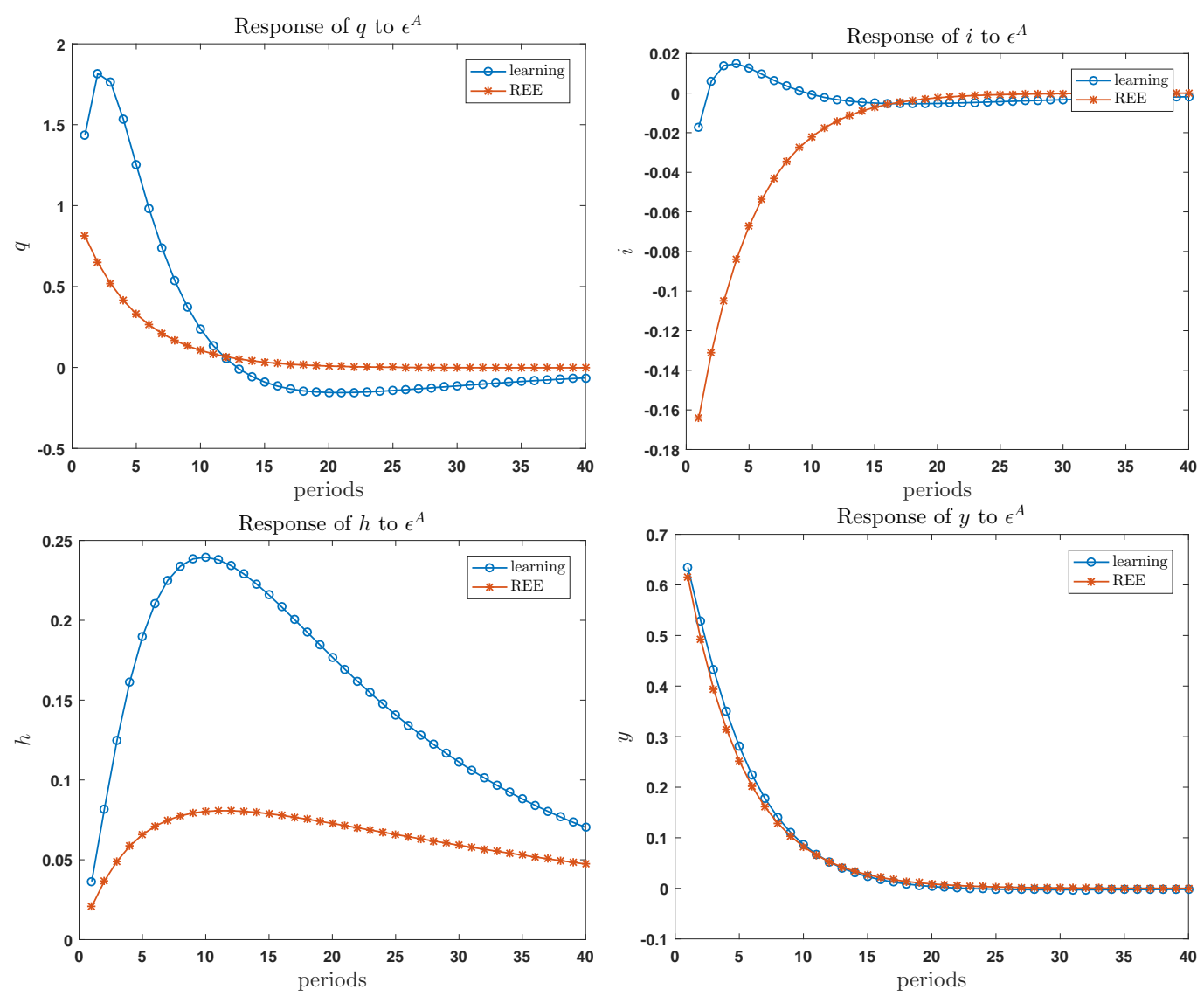

Note: Response to a one standard deviation positive technology shock $\varepsilon_{A t}$. Log percentage points. Flexible prices and zero inflation, with asset production.

does not close the consumption gap $\hat{c}_{t}$ as much as rule 35. Therefore, this extension of the model features a non-trivial policy tradeoff even without cost-push shocks.

With an investment channel present, learning does not only change how monetary policy has to be implemented, but also the optimal target criterion. In Table 2, we compare strict inflation targeting in the absence of cost-push shocks with a particular targeting rule that explicitly "leans against the wind", in that it tolerates inflation below target at times when asset prices are high. This targeting rule would be suboptimal under rational expectations, but turns out to be welfare-increasing under learning.

We also compute optimal simple rules of the form (38) for our calibration of the model

Table 2: "Leaning against the wind" with asset production.

\begin{tabular}{l|ccccc} 
Rational Expectations & $\sigma\left(\pi_{t}\right)$ & $\sigma\left(\hat{y}_{t}\right)$ & $\sigma\left(\Delta \hat{h}_{t}\right)$ & $\sigma\left(\Delta q_{t}\right)$ & $\mathscr{L}$ \\
\hline$\pi_{t}=0$ & 0.000 & 0.000 & 0.000 & 0.850 & 0 \\
\hline Learning & $\sigma\left(\pi_{t}\right)$ & $\sigma\left(\hat{y}_{t}\right)$ & $\sigma\left(\Delta \hat{h}_{t}\right)$ & $\sigma\left(\Delta q_{t}\right)$ & $\mathscr{L}$ \\
\hline$\pi_{t}=0$ & 0.000 & 0.055 & 0.637 & 1.632 & 0.017 \\
$\pi_{t}=-0.009 \cdot \hat{\mu}_{t-1}$ & 0.001 & 0.052 & 0.633 & 1.613 & 0.015 \\
\hline
\end{tabular}


Figure 7: Inflation targeting vs Taylor rule, with asset production.
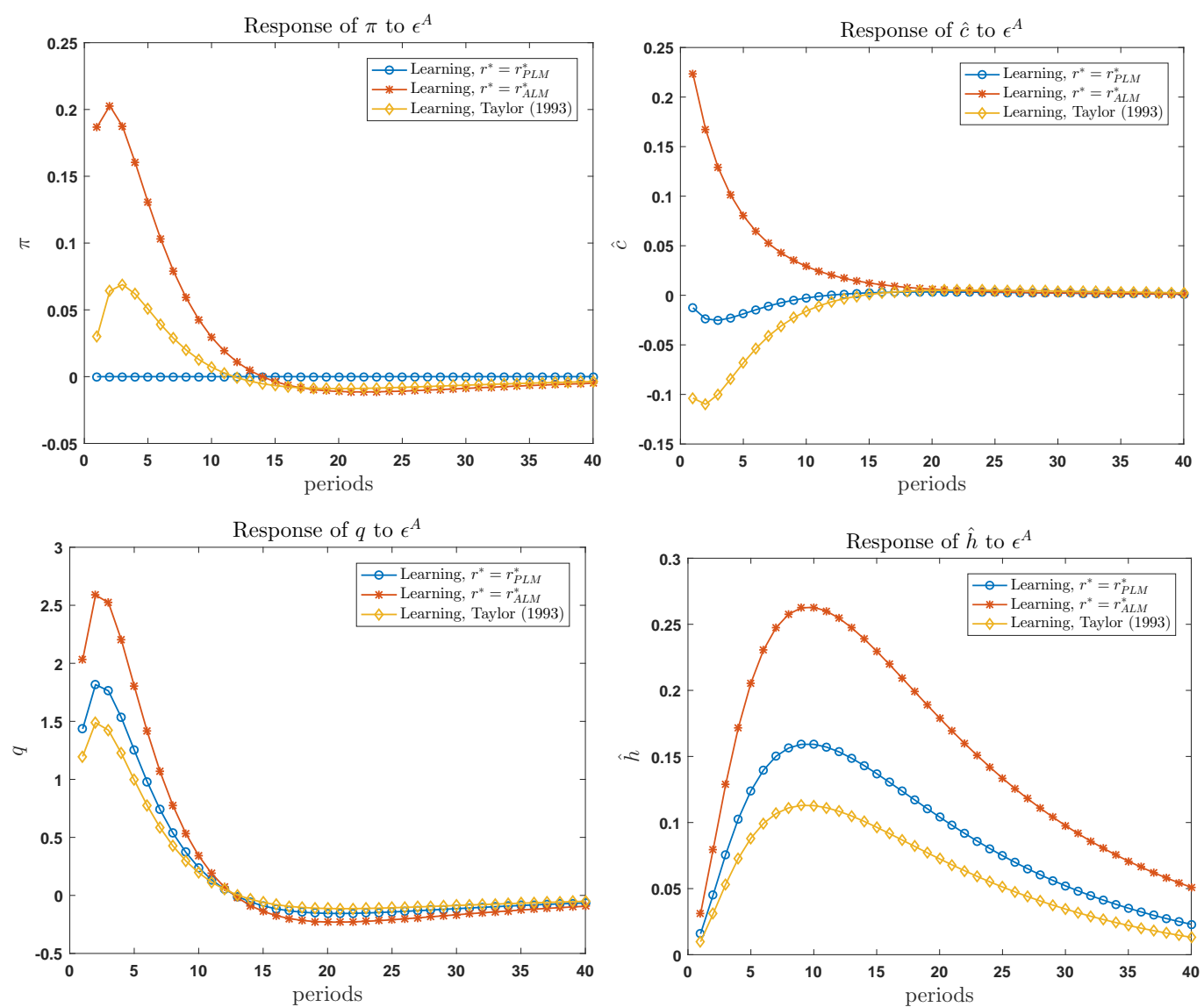

Note: Response to a unit standard deviation positive technology shock $\varepsilon_{A t}$ under sticky prices and with asset production. Log percentage points. The interest rate rules used are given in Equations (35) (using the PLM natural rate with asset production) and (37).

with cost-push shocks, as in section 6. The results are tabulated in Table 3. As was the case with fixed asset supply, the optimal simple rule exhibits a positive response to both asset prices and the output, which can be seen in rows (10) and (11). The optimal rule coefficients prescribe a similar reaction to asset prices and a more aggressive reaction to the output gap under learning than in the case with fixed asset supply. 
Table 3: Performance of optimized simple rules, with asset production.

\begin{tabular}{|c|c|c|c|c|c|c|}
\hline & Rational Expectations & $\sigma\left(\pi_{t}\right)$ & $\sigma\left(\hat{c}_{t}\right)$ & $\sigma\left(\hat{h}_{t}\right)$ & $\sigma\left(\Delta q_{t}\right)$ & $\mathscr{L}$ \\
\hline (1) & $i_{t}=r_{s s}+1.5 \pi_{t}+0.125 \cdot \hat{y}_{t}$ & 0.338 & 0.485 & 0.000 & 0.722 & 3.206 \\
\hline (2) & $\begin{array}{l}i_{t}=\rho_{i}^{*} i_{t-1}+\left(1-\rho_{i}^{*}\right) \cdot\left(r_{s s}+1.5 \pi_{t}+\phi_{y}^{*} \cdot \hat{y}_{t}\right) \\
\left\{\rho_{i}^{*}, \phi_{y}^{*}\right\}=\{0.830,0.116\}\end{array}$ & 0.235 & 0.548 & 0.000 & 0.416 & 1.974 \\
\hline (3) & $\begin{array}{c}\pi_{t}=\zeta^{*} \eta_{t} \\
\zeta^{*}=0.040\end{array}$ & 0.059 & 0.596 & 0.000 & 0.997 & 0.855 \\
\hline & Learning & $\sigma\left(\pi_{t}\right)$ & $\sigma\left(\hat{c}_{t}\right)$ & $\sigma\left(\hat{h}_{t}\right)$ & $\sigma\left(\Delta q_{t}\right)$ & $\mathscr{L}$ \\
\hline (4) & $\begin{array}{l}i_{t}=\rho_{i}^{*} i_{t-1}+\left(1-\rho_{i}^{*}\right) \cdot\left(r_{s s}+1.5 \pi_{t}+\phi_{y}^{*} \cdot \hat{y}_{t}\right) \\
\left\{\rho_{i}^{*}, \phi_{y}^{*}\right\}=\{0,0.069\}\end{array}$ & 0.111 & 0.507 & 0.760 & 1.664 & 0.902 \\
\hline (5) & $\begin{array}{c}\pi_{t}=\zeta^{*} \eta_{t} \\
\zeta^{*}=0.040\end{array}$ & 0.060 & 0.550 & 0.898 & 1.872 & 0.861 \\
\hline (6) & $\begin{array}{l}i_{t}=\rho_{i}^{*} i_{t-1}+\left(1-\rho_{i}^{*}\right) \cdot\left(r_{s s}+1.5 \pi_{t}\right) \\
\rho_{i}^{*}=0\end{array}$ & 0.091 & 0.612 & 0.955 & 1.934 & 1.160 \\
\hline (7) & $\begin{array}{l}\text { BG (1999) w/ asset price } \\
i_{t}=\rho_{i}^{*} i_{t-1}+\left(1-\rho_{i}^{*}\right) \cdot\left(r_{s s}+1.5 \pi_{t}+\phi_{q}^{*} \cdot \log q_{t-1}\right) \\
\quad\left\{\rho_{i}^{*}, \phi_{q}^{*}\right\}=\{0,0.004\}\end{array}$ & 0.077 & 0.619 & 0.955 & 1.991 & 1.126 \\
\hline (8) & $\begin{array}{l}\text { BG (2001) w/ asset price } \\
i_{t}=\rho_{i}^{*} i_{t-1}+\left(1-\rho_{i}^{*}\right) \cdot\left(r_{s s}+1.5 \pi_{t}+\phi_{q}^{*} \cdot \log q_{t}\right) \\
\quad\left\{\rho_{i}^{*}, \phi_{q}^{*}\right\}=\{0,0.005\}\end{array}$ & 0.078 & 0.614 & 0.956 & 1.934 & 1.114 \\
\hline (9) & $\begin{array}{l}i_{t}=\rho_{i}^{*} i_{t-1}+\left(1-\rho_{i}^{*}\right) \cdot\left(r_{s s}+1.5 \pi_{t}+\phi_{q}^{*} \cdot \sum_{s=0}^{\infty} \omega^{* s} \Delta \log Q_{t-s}\right) \\
\left\{\rho_{i}^{*}, \phi_{q}^{*}, \omega^{*}\right\}=\{0,0.007,0.941\}\end{array}$ & 0.075 & 0.608 & 0.953 & 1.916 & 1.083 \\
\hline (10) & $\begin{array}{l}\text { FM }(2007) \text { w/ asset price } \\
\quad i_{t}=\rho_{i}^{*} i_{t-1}+\left(1-\rho_{i}^{*}\right) \cdot\left(r_{s s}+1.5 \pi_{t}+\phi_{y}^{*} \cdot \hat{y}_{t}+\phi_{q}^{*} \cdot \log q_{t}\right) \\
\quad\left\{\rho_{i}^{*}, \phi_{y}^{*}, \phi_{q}^{*}\right\}=\{0.230,0.113,0.015\}\end{array}$ & 0.097 & 0.466 & 0.666 & 1.534 & 0.722 \\
\hline$(11)^{*}$ & $\begin{array}{l}i_{t}=\rho_{i}^{*} i_{t-1}+\left(1-\rho_{i}^{*}\right) \cdot\left(r_{s s}+1.5 \pi_{t}+\phi_{y}^{*} \cdot \hat{y}_{t}+\phi_{q}^{*} \cdot \sum_{s=0}^{\infty} \omega^{* s} \Delta \log Q_{t-s}\right) \\
\left\{\rho_{i}^{*}, \phi_{y}^{*}, \phi_{q}^{*}, \omega^{*}\right\}=\{0.237,0.109,0.016,0.980\}\end{array}$ & 0.093 & 0.469 & 0.669 & 1.532 & 0.709 \\
\hline
\end{tabular}




\section{Conclusion}

In this paper, we have characterized optimal monetary policy in a model in which agents are learning about asset prices. Our model is the standard New-Keynesian model with a durable asset in fixed supply. Agents form expectations about asset price in an extrapolative fashion. However, their expectations remain model-consistent conditional on their beliefs about house prices, which allows us to isolate the effects of learning about asset prices from the many other ways in which distorted beliefs can affect the economy. Learning amplifies asset price fluctuations in the model, and leads to perceived wealth effects that create inefficient fluctuations in consumption, saving, and investment decisions.

We have given an analytical solution to the optimal policy with learning. Our central insight is that the natural real rate of interest under learning depends positively on asset price expectations and realized asset prices. In our baseline model, flexible inflation targeting remains the optimal target criterion for monetary policy, but it requires a very different prescription for the nominal interest rate. Under learning, the interest rate has to increase with asset prices and subjective expectations of future asset price growth.

When we extend the model to allow for asset production, even the optimal target criterion changes and it becomes beneficial to "lean against the wind", i.e. tolerate low inflation when asset prices are high, in order to inefficient investment fluctuations. We have also shown that our theoretical results are robust to the specification of subjective beliefs, encompassing a wide range of belief specifications.

Our model is highly stylized, which has the advantage that we can derive our results analytically. However, the method for computing optimal policy that we present here is readily applicable to larger linear models with learnin. Future work could examine our findings from a more quantitative perspective, for example by estimating the effect of asset price expecations on the natural rate of interest.

\section{References}

Adam, K., KuAng, P. and Marcet, A. (2012). House price booms and the current account. NBER Macroeconomics Annual, 26 (1), 77-122.

— and MARCET, A. (2011). Internal rationality, imperfect market knowledge and asset prices. Journal of Economic Theory, 146 (3), 1224-1252. 
- , - and Beutel, J. (2017). Stock price booms and expected capital gains. American Economic Review, 107 (8), 2352-2408.

—, - and NiCOLINI, J. P. (2015). Stock market volatility and learning. Journal of Finance.

- and Woodford, M. (2018). Leaning Against Housing Prices as Robustly Optimal Monetary Policy. Working Paper 24629, NBER.

Airaudo, M. (2016). Monetary Policy and Asset Prices with Infinite-Horizon Learning. Tech. rep.

Barberis, N., Greenwood, R., Jin, L. and Shleifer, A. (2015). X-CAPM: An extrapolative capital asset pricing model. Journal of Financial Economics, 115 (1), 1-24.

Bernanke, B. S. and Gertler, M. (1999). Monetary policy and asset price volatility. Economic Review - Federal Reserve Bank of Kansas City, Q IV, 17-62.

- and - (2001). Should central banks respond to movements in asset prices? American Economic Review, 91 (2), 253-257.

BILLI, R. M. (2017). Price Level Targeting and Risk Management. Working Paper Series 302, Sveriges Riksbank.

Boenm, C. E. and House, C. L. (2014). Optimal Taylor Rules in New Keynesian Models. Working Paper 20237, NBER.

Bordalo, P., Gennaiola, N. and Shleifer, A. (2018). Diagnostic expectations and credit cycles. Journal of Finance, 73 (1), 199-227.

Caines, C. (2016). Can Learning Explain Boom-Bust Cycles In Asset Prices? An Application to the US Housing Boom. International Finance Discussion Papers 1181, Board of Governors of the Federal Reserve System (U.S.).

Christiano, L., Ilut, C., Motto, R. and Rostagno, M. (2010). Monetary policy and stock market booms. Proceedings, Jackson Hole Economic Policy Symposium, pp. 85-145.

Collin-Dufresne, P., Johannes, M. and Lochstoer, L. A. (2013). Parameter Learning in General Equilibrium: The Asset Pricing Implications. NBER Working Papers 19705, National Bureau of Economic Research, Inc.

Dong, F., MiaO, J. and Wang, P. (2017). Asset Bubbles and Monetary Policy. Working paper. 
DUPOR, B. (2005). Stabilizing non-fundamental asset price movements under discretion and limited information. Journal of Monetary Economics, 52 (4), 727 - 747.

Eusepi, S., Giannoni, M. and Preston, B. (2015). The Limits of Monetary Policy with Long-term Drift in Expectations. Working paper.

- and Preston, B. (2016). The science of monetary policy: an imperfect knowledge perspective. Staff Reports 782, Federal Reserve Bank of New York.

FAIA, E. and MONACELli, T. (2007). Optimal interest rate rules, asset prices, and credit frictions. Journal of Economic Dynamics and Control, 31 (10), 3228-3254.

Fuster, A., Hebert, B. and Laibson, D. (2012). Natural expectations, macroeconomic dynamics, and asset pricing. In D. Acemoglu and M. Woodford (eds.), NBER Macroeconomics Annual 2011, NBER Chapters, vol. 26, National Bureau of Economic Research, pp. 1-48.

GALI, J. (2014). Monetary policy and rational asset price bubbles. American Economic Review, 104 (3), 721-752.

- (2017). Monetary Policy and Bubbles in a New Keynesian Model with Overlapping Generations. Working Paper 959, Barcelona GSE.

Gandelman, N. and Hernández-Murillo, R. (2014). Risk Aversion at the Country Level. Working paper series, Federal Reserve Bank of St. Louis.

GANDRÉ, P. (2017). Learning, house prices and macro-financial linkages. Working paper.

Glaeser, E. L. and NAthanson, C. G. (2017). An extrapolative model of house price dynamics. Journal of Financial Economics.

GREENSPAN, A. (1996). Remarks at the annual dinner and francis boyer lecture of the american enterprise institute for public policy research, washington, d.c.

Greenwood, R. and Shleifer, A. (2014). Expectations of returns and expected returns. Review of Financial Studies, 27 (3), 714-746.

Harding, J. P., Rosenthal, S. S. and Sirmans, C. (2007). Depreciation of housing capital, maintenance, and house price inflation: Estimates from a repeat sales model. Journal of Urban Economics, 61 (2), 193 - 217.

LAUBACH, T. and WiLliams, J. C. (2016). Measuring the natural rate of interest redux. Business Economics, 51, 257-267. 
Mertens, T. M. (2011). Volatile Stock Markets: Equilibrium Computation and Policy Analysis. Working paper, Federal Reserve Bank of San Francisco.

MolnAR, K. and SANTORO, S. (2014). Optimal monetary policy when agents are learning. European Economic Review, 66, 39 - 62.

NEISS, K. S. and NELSON, E. (2003). The real-interest-rate gap as an inflation indicator. Macroeconomic Dynamics, 7 (2), 239-262.

Preston, B. (2006). Adaptive learning, forecast-based instrument rules and monetary policy. Journal of Monetary Economics, 53 (3), 507 - 535.

SAIZ, A. (2010). The geographic determinants of housing supply. Quarterly Journal of Economics, 125 (3), 1253-1296.

SVENSSON, L. E. (2017). Cost-benefit analysis of leaning against the wind. Journal of Monetary Economics, 90, 193 - 213.

WinkLER, F. (2016). The Role of Learning for Asset Prices, Business Cycles, and Monetary Policy. Finance and Economics Discussion Series 2016-019, Federal Reserve Board of Governors.

WOODFORD, M. (2003). Interest and prices: Foundations of a theory of monetary policy. Princeton University Press.

- (2010). Robustly optimal monetary policy with near-rational expectations. American Economic Review, 100 (1), 274-303. 


\section{A Appendix: Details on the derivations}

\section{A.1 Asset demand in the model with fixed asset supply}

The coefficients in the asset demand function (24) are:

$$
\begin{aligned}
& k_{h}=\frac{1}{2 \beta}\left(1+\beta+\frac{\theta}{\gamma \kappa_{1}}(1-\beta)-\sqrt{\left(1+\beta+\frac{\theta}{\gamma \kappa_{1}}(1-\beta)\right)^{2}-4 \beta}\right) \in(0,1) \\
& k_{a}=\frac{1+\phi}{1+\phi-\alpha(1-\gamma)} \frac{1-\beta \rho_{a}}{\kappa_{1}+(1-\beta) \frac{\theta}{\gamma}+\beta \kappa_{1}\left(1-k_{h}-\rho_{a}\right)}>0 \\
& k_{q}=\frac{1}{\gamma} \frac{1-\beta}{(1-\beta) \frac{\theta}{\gamma}+\kappa_{1}\left(1-\beta k_{h}\right)}>0 \\
& k_{\mu}=\frac{\beta / \gamma}{(1-\beta) \frac{\theta}{\gamma}+\kappa_{1}\left(1-\beta \rho_{\mu}+\beta\left(1-k_{h}\right)\right)} \frac{(1+\beta) \frac{\theta}{\gamma}+\kappa_{1} \beta\left(1-k_{h}\right)}{(1+\beta) \frac{\theta}{\gamma}+\kappa_{1}\left(1-\beta k_{h}\right)}>0
\end{aligned}
$$

\section{A.2 Asset demand with extended beliefs}

The coefficients $\tilde{k}_{\mu}$ and $\tilde{\rho}$ read as follows:

$$
\begin{aligned}
\tilde{k}_{\mu} & =\frac{1}{\gamma} \frac{\beta}{(1-\beta) \frac{\theta}{\gamma}+\kappa_{1}\left(1+\beta-\beta k_{h}\right)} \frac{(1+\beta) \frac{\theta}{\gamma}+\kappa_{1} \beta\left(1-k_{h}\right)}{(1+\beta) \frac{\theta}{\gamma}+\kappa_{1}\left(1-\beta k_{h}\right)}>0 \\
\tilde{\rho} & =\frac{\beta}{\beta+(1-\beta) \frac{\theta}{\gamma \kappa_{1}}+\left(1-\beta k_{h}\right)} \in(0,1) .
\end{aligned}
$$

\section{A.3 Attaining the first-best allocation with cost push shocks under learning}

Substituting the policy $\pi_{t}=-\left(\beta \rho_{\eta}\right)^{-1} \eta_{t}+b_{t} z_{t}$ into the Phillips curve (30), we obtain:

$$
\pi_{t}=-\left(\beta \rho_{\eta}\right)^{-1} \eta_{t}+b_{t} z_{t}=\kappa\left(\tilde{c}_{t}+\kappa_{1} \Delta \tilde{h}_{t}\right)
$$

We will find $b_{t}$ such that $\pi_{t}=0$ a.s. under the ALM. In this case, $\tilde{c}_{t}+\kappa_{1} \Delta \tilde{h}_{t}=y_{t}-y_{t}^{R E}=0$ under the ALM as well, and the first-best allocation is attained.

In order to solve for $b_{t}$, then, we need to compute the equilibrium value of $z_{t}$, which amounts to solving for the equilibrium price $q_{t}$. To do this, we first need to derive the demand function for the asset under the PLM. Let $x_{t}=\tilde{c}_{t}+\kappa_{1} \Delta \tilde{h}_{t}$. In analogy to 
the computations of the flexible-price equilibrium, we can compute the asset demand function as the solution to the following system of equations:

$$
\begin{gathered}
(1-\beta) \theta h_{t}=\gamma c_{t}-q_{t}-\beta \mathbb{E}_{t}^{\mathscr{P}}\left[\gamma c_{t+1}-q_{t+1}\right] \\
(1+\phi-\alpha+\alpha \gamma) c_{t}=\alpha x_{t}+(1-\alpha) a_{t}-(1+\phi-\alpha) \frac{\bar{Q} \bar{H}}{\bar{Y}} \Delta h_{t} .
\end{gathered}
$$

With $x_{t}=\left(b_{t} z_{t}-\left(\beta \rho_{\eta}\right)^{-1} \eta_{t}\right) / \kappa$, we can solve:

$$
h_{t}=k_{h} h_{t-1}+k_{a} a_{t}-k_{q} q_{t}+k_{\mu} \hat{\mu}_{t-1}+k_{b z} b_{t} z_{t}+k_{\eta} \eta_{t}
$$

Here, the coefficients $k_{h}, k_{a}, k_{q}$ and $k_{\mu}$ are the same as in the flexible-price demand function (24). The coefficients $k_{\eta}$ and $k_{b z}$ are given by:

$$
\begin{aligned}
k_{\eta} & =-\frac{k_{h}}{\beta \rho_{\eta} \kappa} \frac{1-\beta \rho_{\eta}}{1-k_{h} \beta \rho_{\eta}} \frac{\bar{Y}}{\bar{Q} \bar{H}} \frac{\alpha}{1+\phi-\alpha} \\
k_{z, t} & =-\frac{k_{h}}{\kappa} \frac{\bar{Y}}{\bar{Q} \bar{H}} \frac{\alpha}{1+\phi-\alpha}
\end{aligned}
$$

Now the ALM is found by imposing $h_{t}=0$, and this condition leads to the ALM expression for $z_{t}$ :

$$
z_{t}=\frac{k_{q}}{k_{q}-k_{b z} b_{t}}\left(\frac{1}{k_{q}}\left(k_{a} a_{t}+k_{\mu} \hat{\mu}_{t-1}+k_{\eta} \eta_{t}\right)-q_{t-1}-\hat{\mu}_{t-1}\right)
$$

Imposing $\beta \rho_{\eta} b_{t} z_{t}=\eta_{t}$ then leads to:

$$
b_{t}=\left(\frac{k_{b z}}{k_{q}}+\frac{\beta \rho_{\eta}}{k_{q}}\left(k_{a} a_{t}+k_{\mu} \hat{\mu}_{t-1}+k_{\eta} \eta_{t}\right)-\beta \rho_{\eta}\left(q_{t-1}+\hat{\mu}\right)\right)^{-1} \eta_{t} .
$$

\section{A.4 Optimal $\mathbb{P}$-measurable policy with cost-push shocks}

Proof of Proposition 3. We first restate the Phillips curve (30) in terms of marginal cost:

$$
\pi_{t}=\beta \mathbb{E}_{t}^{\mathscr{P}} \pi_{t+1}+\frac{(1-\xi)(1-\beta \xi)}{\xi} m_{t}+\eta_{t}
$$

When $\left(\pi_{t}\right)_{t=0}^{\infty}$ is $u_{t}$-measurable, then it has the same distribution under the subjective belief measure $\mathscr{P}$ as under the actual belief measure $\mathbb{P}$. We can therefore write $\mathbb{E}_{t}^{\mathscr{P}} \pi_{t}=\mathbb{E}_{t} \pi_{t+1}$. The Phillips curve above then implies that the marginal cost $m_{t}$ is also $u_{t}$-measurable. Furthermore, combining the static equilibrium conditions for labor supply and demand, the production function and the household budget constraint, 
we obtain:

$$
\frac{1+\phi-\alpha+\alpha \gamma}{\alpha} y_{t}=m_{t}+\frac{1+\phi}{\alpha} a_{t}+\gamma \frac{\bar{Q} \bar{H}}{\bar{Y}} \Delta h_{t}
$$

This equation has to hold both under the PLM, the ALM, and under RE, since it does not involve expectations. Furthermore, under the ALM we have $\Delta h_{t}^{*}=0$, while under $\mathrm{RE}$ and flexible prices, we have $\Delta h_{t}=0$ and $m_{t}=0$. Together, these conditions imply that equilibrium output under learning equals $y_{t}^{*}=\alpha /(1+\phi-\alpha+\alpha \gamma) m_{t}+y_{t}^{n, R E}$. We can therefore write the policy problem under learning as follows:

$$
\begin{gathered}
\max \sum_{t=0}^{\infty} \beta^{t}\left(\lambda \pi_{t}^{2}+\hat{y}_{t}^{2}\right) \\
\text { s.t. } \pi_{t}=\beta \mathbb{E}_{t} \pi_{t+1}+\frac{(1-\xi)(1-\beta \xi)}{\xi} m_{t}+\eta_{t} \\
\hat{y}_{t}=\frac{\alpha}{1+\phi-\alpha+\alpha \gamma} m_{t} .
\end{gathered}
$$

It is clear then that this problem is isomorphic to that of a policymaker under rational expectations. The solutions to the now standard commitment and discretion policies establish parts (1) and (2) of the proposition.

To prove part (3) of the proposition, we write the IS equation (31) as

$$
i_{t}=r_{t}^{n}+\mathbb{E}_{t}^{\mathscr{P}} \pi_{t+1}+\gamma \mathbb{E}_{t}^{\mathscr{P}} \Delta \tilde{c}_{t+1} .
$$

Let $\phi_{\pi}>1$. The optimality conditions for $\pi_{t}$ in cases (1) and (2) combined with (30) and (32) imply that $\left(\pi_{t}\right)_{t=0}^{\infty}$ and $\left(\tilde{c}_{t}\right)_{t=0}^{\infty}$ are linear processes of the cost-push shock $\eta_{t}$ only. Therefore, we can evaluate $\mathbb{E}_{t}^{\mathscr{P}} \pi_{t+1}+\gamma \mathbb{E}_{t}^{\mathscr{P}} \Delta \tilde{c}_{t+1}-\phi_{\pi} \pi_{t}=A(L) \eta_{t}$ for some lag polynomial $A(L)$. IF the central bank sets $i_{t}=r_{t}^{n}+A(L) \eta_{t}+\phi_{\pi} \pi_{t}$, then this interest rate rule satisfies the Taylor principle, therefore guaranteeing a unique equilibrium, and by construction implements the optimal allocation in either of the cases (1) and (2) above.

\section{A.5 Linearized equilibrium conditions and natural rate in the model with asset production}

Under rational expectations, the following set of equations describe the linearized equilibrium (up to a monetary policy rule): 


$$
\begin{aligned}
y_{t} & =a_{t}+\alpha n_{t} \\
w_{t} & =m_{t}+a_{t}-(1-\alpha) n_{t} \\
\pi_{t} & =\beta \pi_{t+1}+\frac{(1-\xi)(1-\beta \xi)}{\xi} m_{t}+\eta_{t} \\
w_{t} & =\gamma c_{t}+\phi n_{t} \\
\bar{Y} y_{t} & =\bar{C} c_{t}+\bar{Q} \bar{H} \delta x_{t} \\
\delta x_{t} & =h_{t}-(1-\delta) h_{t-1} \\
x_{t} & =\frac{\omega}{1-\omega} q_{t} \\
i_{t} & =\gamma\left(\mathbb{E}_{t} c_{t+1}-c_{t}\right)+\mathbb{E}_{t} \pi_{t+1} \\
q_{t}+(1-\beta(1-\delta)) \theta h_{t} & =\gamma c_{t}+\beta(1-\delta) \mathbb{E}_{t}\left(q_{t+1}-\gamma c_{t+1}\right) .
\end{aligned}
$$

The flexible price equilibrium under rational expectations is characterized as:

$$
\begin{aligned}
h_{t}^{n, R E} & =k_{a}^{R E} a_{t}+k_{h}^{R E} h_{t-1}^{R E}, k_{a}^{R E}>0, k_{h}^{R E} \in(0,1-\delta) \\
y_{t}^{n, R E} & =\left(\frac{\bar{C}}{\bar{Y}} \frac{\phi+1}{\frac{\bar{C}}{\bar{Y}}(1+\phi-\alpha)+\alpha \gamma}+\left(\frac{\delta \bar{Q} \bar{H}}{\bar{Y}}-\frac{\bar{C}}{\bar{Y}} \kappa_{1}\right) \frac{k_{a}^{R E}}{\delta}\right) a_{t}-\left(\frac{\delta \bar{Q} \bar{H}}{\bar{Y}}-\frac{\bar{C}}{\bar{Y}} \kappa_{1}\right) \frac{1-\delta-k_{h}^{R E}}{\delta} h_{t-1}^{R E} \\
c_{t}^{n, R E} & =\left(\frac{\phi+1}{\frac{\bar{C}}{\bar{Y}}(1+\phi-\alpha)+\alpha \gamma}-\kappa_{1} \frac{k_{a}^{R E}}{\delta}\right) a_{t}+\kappa_{1} \frac{1-\delta-k_{h}^{R E}}{\delta} h_{t-1}^{R E} \\
r_{t}^{n, R E} & =-\gamma\left(\frac{\phi+1}{\frac{\bar{C}}{\bar{Y}}(1+\phi-\alpha)+\alpha \gamma}-\kappa_{1} \frac{k_{a}^{R E}}{\delta}+\kappa_{1} \frac{1-\delta-k_{h}^{R E}}{\delta} k_{a}^{R E}\right)\left(1-\rho_{a}\right) a_{t} \\
& -\gamma \kappa_{1} \frac{1-\delta-k_{h}^{R E}}{\delta}\left(1-k_{h}^{R E}\right) h_{t-1}^{R E}
\end{aligned}
$$

where the coefficients $k_{h}^{R E}$ and $k_{a}^{R E}$ are given by:

$$
\begin{aligned}
& k_{h}^{R E}=\frac{1}{2 \tilde{\beta}}\left(1+\tilde{\beta}(1-\delta)+\frac{\theta}{\gamma} \frac{(1-\tilde{\beta}) \delta}{\kappa_{1}+\frac{1-\omega}{\gamma \omega}}-\sqrt{\left(1+\tilde{\beta}(1-\delta)+\frac{\theta}{\gamma} \frac{(1-\tilde{\beta}) \delta}{\kappa_{1}+\frac{1-\omega}{\gamma \omega}}\right)^{2}-4 \tilde{\beta}(1-\delta)}\right) \in(0,1-\delta) \\
& k_{a}^{R E}=\frac{1+\phi}{\frac{\bar{C}}{\bar{Y}}(1+\phi-\alpha)+\alpha \gamma} \frac{1-\tilde{\beta} \rho_{a}}{(1-\tilde{\beta}) \frac{\theta}{\gamma}+\delta^{-1}\left(\kappa_{1}+\frac{1-\omega}{\gamma \omega}\right)\left(1+\tilde{\beta}\left(1-\delta-k_{h}-\rho_{a}\right)\right)}>0 .
\end{aligned}
$$


The sticky-price RE equilibrium is characterized in deviation from the flexible price equilibrium through the equations:

$$
\begin{aligned}
\pi_{t} & =\beta \mathbb{E}_{t}^{\mathscr{P}} \pi_{t+1}+\kappa\left(\hat{c}_{t}+\kappa_{1} \hat{x}_{t}\right)+\eta_{t} \\
i_{t} & =\gamma\left(\mathbb{E}_{t} \hat{c}_{t+1}-\hat{c}_{t}\right)+\mathbb{E}_{t} \pi_{t+1}+r_{t}^{n} \\
\theta(1-\tilde{\beta}) \hat{h}_{t} & =\tilde{\beta} \mathbb{E}_{t}\left(\frac{1-\omega}{\omega} \hat{x}_{t+1}-\gamma \hat{c}_{t+1}\right)-\left(\frac{1-\omega}{\omega} \hat{x}_{t}-\gamma \hat{c}_{t}\right) .
\end{aligned}
$$

Under learning, we can do a similar exercise. We first tackle the PLM. All we do is to replace the market clearing condition (56) with the subjective law of motion for asset prices:

$$
\begin{aligned}
y_{t} & =a_{t}+\alpha n_{t} \\
w_{t} & =m_{t}+a_{t}-(1-\alpha) n_{t} \\
\pi_{t} & =\beta \mathbb{E}_{t}^{\mathscr{P}} \pi_{t+1}+\frac{(1-\xi)(1-\beta \xi)}{\xi} m_{t}+\eta_{t} \\
w_{t} & =\gamma c_{t}+\phi n_{t} \\
\bar{Y} y_{t} & =\bar{C} c_{t}+\bar{Q} \bar{H}\left(h_{t}-(1-\delta) h_{t-1}\right) \\
i_{t} & =\gamma\left(\mathbb{E}_{t}^{\mathscr{P}} c_{t+1}-c_{t}\right)+\mathbb{E}_{t}^{\mathscr{P}} \pi_{t+1} \\
q_{t} & =\gamma c_{t}-(1-\beta(1-\delta)) \theta h_{t}-\beta(1-\delta) \gamma \mathbb{E}_{t}^{\mathscr{P}} c_{t+1}+\beta(1-\delta) \mathbb{E}_{t}^{\mathscr{P}} q_{t+1} \\
q_{t} & =q_{t-1}+\hat{\mu}_{t-1}+z_{t} \\
\hat{\mu}_{t} & =\rho_{\mu} \hat{\mu}_{t-1}+g z_{t} .
\end{aligned}
$$

Under learning and flexible prices, we can boil things down to these two equations to solve for the PLM:

$$
\begin{aligned}
0 & =\gamma c_{t}+\left(\frac{1+\phi-\alpha}{\alpha}\right)\left(\frac{\bar{C}}{\bar{Y}} c_{t}+\frac{\bar{Q} \bar{H}}{\bar{Y}} \tilde{h}_{t}\right)-\frac{1+\phi}{\alpha} a_{t} \\
q_{t} & =\gamma c_{t}-(1-\tilde{\beta}) \theta h_{t}-\tilde{\beta} \gamma \mathbb{E}_{t} c_{t+1}+\beta \delta \mathbb{E}_{t}^{\mathscr{P}} q_{t+1} .
\end{aligned}
$$

Guess and verify

$$
h_{t}^{n}=k_{a} a_{t}+k_{h} h_{t-1}^{n}-k_{q} q_{t}+k_{\mu} \hat{\mu}_{t-1}
$$


where the coefficients are given by:

$$
\begin{aligned}
& k_{h}=\frac{1}{2 \tilde{\beta}}\left(1+\tilde{\beta}(1-\delta)+\frac{\theta \delta}{\gamma \kappa_{1}}(1-\tilde{\beta})-\sqrt{\left(1+\tilde{\beta}(1-\delta)+\frac{\theta \delta}{\gamma \kappa_{1}}(1-\tilde{\beta})\right)^{2}-4 \tilde{\beta}(1-\delta)}\right) \in(0,1-\delta) \\
& k_{a}=\frac{1+\phi}{\frac{\bar{C}}{\bar{Y}}(1+\phi-\alpha)+\alpha \gamma} \frac{1-\tilde{\beta} \rho_{a}}{(1-\tilde{\beta}) \frac{\theta}{\gamma}+\kappa_{1} \delta^{-1}\left(1+\tilde{\beta}\left(1-\delta-k_{h}-\rho_{a}\right)\right)}>0 \\
& k_{q}=\frac{1}{\gamma} \frac{1-\tilde{\beta}}{(1-\tilde{\beta}) \frac{\theta}{\gamma}+\kappa_{1} \delta^{-1}\left(1-\tilde{\beta} k_{h}-\tilde{\beta} \delta\right)}>0 \\
& k_{\mu}=\frac{\tilde{\beta} / \gamma}{(1-\tilde{\beta}) \frac{\theta}{\gamma}+\kappa_{1} \delta^{-1}\left(1-\tilde{\beta} \rho_{\mu}+\tilde{\beta}\left(1-\delta-k_{h}\right)\right)} \frac{(1-\tilde{\beta}) \frac{\theta}{\gamma}+\kappa_{1} \delta^{-1} \tilde{\beta}\left(1-\delta-k_{h}\right)}{(1-\tilde{\beta}) \frac{\theta}{\gamma}+\kappa_{1} \delta^{-1}\left(1-\tilde{\beta} k_{h}-\tilde{\beta} \delta\right)}>0
\end{aligned}
$$

where $\tilde{\beta}=(1-\delta) \beta$. We can characterize the flex-price PLM investment, consumption, output and interest rates:

$$
\begin{aligned}
x_{t}^{n} & =x_{t}^{n, R E}+\frac{1}{\delta}\left(h_{t}^{n}-h_{t}^{n, R E}\right)-\frac{1-\delta}{\delta}\left(h_{t-1}^{n}-h_{t-1}^{n, R E}\right) \\
c_{t}^{n} & =c_{t}^{n, R E}-\kappa_{1}\left(x_{t}^{n}-x_{t}^{n, R E}\right) \\
y_{t}^{n} & =y_{t}^{n, R E}+\left(\frac{\bar{Q} \bar{H}}{\bar{Y}}-\frac{\bar{C}}{\bar{Y}} \kappa_{1}\right)\left(x_{t}^{n}-x_{t}^{n, R E}\right) \\
-\frac{r_{t}^{n, P L M}-r_{t}^{n, R E}}{\gamma \kappa_{1}} & =-\left(\left(1-k_{h}\right)\left(1-\delta-k_{h}\right)-\left(1-k_{h}^{R E}\right)\left(1-\delta-k_{h}^{R E}\right)\right) h_{t-1} \\
& -\left(1-k_{h}^{R E}\right)\left(1-\delta-k_{h}^{R E}\right)\left(h_{t-1}^{n}-h_{t-1}^{n, R E}\right) \\
& +\left(k_{a}\left(2-\delta-k_{a}-\rho_{a}\right)-k_{a}^{R E}\left(2-\delta-k_{a}^{R E}-\rho_{a}\right)\right) a_{t} \\
& +\left(k_{\mu}\left(2-\delta-k_{h}-\rho_{\mu}\right)+k_{q}\right) \hat{\mu}_{t-1}-k_{q}\left(1-\delta-k_{h}\right) q_{t}
\end{aligned}
$$

In order to find the ALM under flexible prices, we impose market clearing for the asset and obtain:

$$
\begin{aligned}
\frac{\omega \delta}{1-\omega} q_{t}^{*} & =k_{a} a_{t}+k_{h} h_{t-1}^{*}-k_{q} q_{t}^{*}+k_{\mu} \hat{\mu}_{t-1}^{*}-(1-\delta) h_{t-1}^{*} \\
\Leftrightarrow q_{t}^{*} & =\frac{1}{\frac{\omega}{1-\omega} \delta+k_{q}}\left(k_{a} a_{t}+k_{\mu} \hat{\mu}_{t-1}^{*}-\left(1-\delta-k_{h}\right) h_{t-1}^{*}\right) .
\end{aligned}
$$

The equilibrium price is increasing in productivity, increasing in asset price beliefs, and decreasing in the existing stock of housing.

When the equilibrium asset price $q_{t}$ from equation (81) is substituted into the expression for the natural rate $r_{t}^{n}$, the natural real rate in the ALM $r_{t}^{n *}$ is increasing in asset price expectations $\hat{\mu}_{t-1}^{*}$, just as in the baseline model. The sign of the other coefficients 
are ambiguous and depend on the parameterization.

We can write the PLM under sticky prices in deviation from the flexible price PLM as follows:

$$
\begin{aligned}
\pi_{t} & =\beta \mathbb{E}_{t}^{\mathscr{P}} \pi_{t+1}+\kappa\left(\tilde{c}_{t}+\kappa_{1} \tilde{x}_{t}\right)+\eta_{t} \\
i_{t} & =\gamma\left(\mathbb{E}_{t}^{\mathscr{P}} \tilde{c}_{t+1}-\tilde{c}_{t}\right)+\mathbb{E}_{t}^{\mathscr{P}} \pi_{t+1}+r_{t}^{n} \\
\theta(1-\tilde{\beta}) \tilde{h}_{t} & =\gamma \tilde{c}_{t}-\tilde{\beta} \gamma \mathbb{E}_{t}^{\mathscr{P}} \tilde{c}_{t+1} .
\end{aligned}
$$

\section{A.6 Optimal $\mathbb{P}$-measurable policy with production}

Proof of Proposition 4. We start by rewriting the welfare-based loss function (49) in a suitable form. By expanding $\bar{Y} \hat{y}_{t}=\bar{C} \hat{c}_{t}+\delta \bar{Q} \bar{H} \hat{x}_{t}$ and rearranging terms, we obtain:

$$
\begin{aligned}
\mathscr{L}_{t} & =2 \sigma \frac{\xi}{1-\xi} \frac{1}{1-\beta \xi}\left(\pi_{t}^{*}\right)^{2}+\left(\gamma+\frac{1+\phi-\alpha}{\alpha} \frac{\bar{C}}{\bar{Y}}\right) \frac{\bar{C}}{\bar{Y}}\left(\hat{c}_{t}+\kappa_{1} \hat{x}_{t}\right)^{2} \\
& +(1-\beta(1-\delta)) \theta \frac{\bar{Q} \bar{H}}{\bar{Y}} \hat{h}_{t}^{2}+\frac{\bar{Q} \bar{H}}{\bar{Y}}\left((1-\omega) \delta^{2}+\gamma \delta \kappa_{1}\right) \hat{x}_{t}^{2} .
\end{aligned}
$$

We now note from the Phillips curve that $c_{t}+\kappa_{1} x_{t}=\alpha /\left(\frac{\bar{C}}{\bar{Y}}(1+\phi-\alpha)+\alpha \gamma\right) m_{t}$ and $m_{t}=$ 0 under flexible prices. Therefore, we can rewrite $\hat{c}_{t}+\kappa_{1} \hat{x}_{t}=\alpha /\left(\frac{\bar{C}}{\bar{Y}}(1+\phi-\alpha)+\alpha \gamma\right) m_{t}^{*}$. Dividing through the (positive) coefficient on $m_{t}^{*}$, we can bring the loss function into the form

$$
\mathscr{L}_{t}=\lambda\left(\pi_{t}^{*}\right)^{2}+\left(m_{t}^{*}\right)^{2}+\ell_{x} \hat{x}_{t}^{2}+\ell_{h} \hat{h}_{t}^{2}
$$

where $\lambda, \ell_{x}, \ell_{h}>0$.

Next, we note that, when $\left(\pi_{t}\right)_{t=0}^{\infty}$ is $u_{t}$-measurable, then it has the same distribution under the subjective belief measure $\mathscr{P}$ as under the actual belief measure $\mathbb{P}$. Equations (46) and (48) then imply that $\tilde{c}_{t}, \tilde{h}_{t}$ and $m_{t}$ are also $u_{t}$-measurable.

Finally, the policymaker needs to take into account the effect of her actions on the equilibrium asset price $q_{t}$, which depends on investment $x_{t}=x_{t}^{n}+\tilde{x}_{t}$ through the market clearing condition (56). To determine the flex-price level of investment $x_{t}^{n}$, we make use of the closed-form expression for $h_{t}^{n}$ derived in (77). Finally, we have to take into account the effect of prices $q_{t}$ on beliefs $\hat{\mu}_{t}$, which are given by (73)-(74).

In sum, the policymaker's commitment problem can be described as follows:

$$
\max \frac{1}{2} \sum_{t=0}^{\infty} \beta^{t}\left(\lambda \pi_{t}^{2}+m_{t}^{2}+\ell_{x} \hat{x}_{t}^{2}+\ell_{h} \hat{h}_{t}^{2}\right)
$$




$$
\begin{aligned}
\text { s.t. } \pi_{t} & =\beta \mathbb{E}_{t} \pi_{t+1}+\frac{(1-\xi)(1-\beta \xi)}{\xi} m_{t} & \left(\mu_{t}\right) \\
\theta(1-\tilde{\beta}) \tilde{h}_{t} & =\frac{\alpha \gamma}{\frac{\bar{C}}{\bar{Y}}(1+\phi-\alpha)+\alpha \gamma}\left(m_{t}-\tilde{\beta} \mathbb{E}_{t} m_{t+1}\right)-\gamma \kappa_{1}\left(\tilde{x}_{t}-\tilde{\beta} \mathbb{E}_{t}^{\mathscr{P}} \tilde{x}_{t+1}\right) & \left(\chi_{t}\right) \\
\hat{h}_{t} & =\tilde{h}_{t}+h_{t}^{n}-h_{t}^{n, R E} & \left(\hat{\psi}_{t}\right) \\
h_{t}^{n} & =k_{a} a_{t}+k_{h} h_{t-1}^{n}-k_{q} q_{t}+k_{\mu} \hat{\mu}_{t-1} & \left(\psi_{t}\right) \\
\frac{\omega}{1-\omega} q_{t} & =x_{t}^{n}+\tilde{x}_{t} & \left(\Omega_{q t}\right) \\
\hat{\mu}_{t} & =\rho_{\mu} \hat{\mu}_{t-1}+g\left(\Delta q_{t}-\hat{\mu}_{t-1}\right) . & \left(\Omega_{\mu t}\right)
\end{aligned}
$$

Note that we have substituted out $\tilde{c}_{t}$ in the constraints of the problem. The multipliers attached to the constraints are in parentheses.

The first-order conditions of the planner are:

$$
\begin{aligned}
& \lambda \pi_{t}=\Delta \mu_{t} \\
& \mu_{t}=-\frac{\xi}{(1-\xi)(1-\beta \xi)} m_{t}-\frac{1}{\kappa}\left(\chi_{t}-(1-\delta) \chi_{t-1}\right) \\
& \theta(1-\tilde{\beta}) \chi_{t}=\gamma \frac{\kappa_{1}}{\delta}\left(\tilde{\beta} \mathbb{E}_{t}\left(\chi_{t+1}-(1-\delta) \chi_{t}\right)-\chi_{t}+(1-\delta) \chi_{t-1}\right) \\
&+\hat{\psi}_{t}+\frac{\Omega_{q t}-\tilde{\beta} \mathbb{E}_{t} \Omega_{q t+1}}{\delta} \\
& \hat{\psi}_{t}=\ell_{h} \hat{h}_{t}+\ell_{x} \frac{\hat{x}_{t}-\tilde{\beta} \mathbb{E}_{t} \hat{x}_{t+1}}{\delta} \\
& \psi_{t}=\hat{\psi}_{t}+\beta k_{h} \mathbb{E}_{t} \psi t+1+\frac{\Omega_{q t}-\tilde{\beta} \mathbb{E}_{t} \Omega_{q t+1}}{\delta} \\
& \frac{\omega}{1-\omega} \Omega_{q t}=g\left(\Omega_{\mu t}-\beta \mathbb{E}_{t} \Omega_{\mu t+1}\right)-k_{q} \psi_{t} \\
& \Omega_{\mu t}=\beta k_{\mu} \mathbb{E}_{t} \psi t+1 \\
&
\end{aligned}
$$

We can combine optimality conditions (85) and (86) into

$$
\lambda \kappa p_{t}=-\frac{\overline{\bar{Y}}(1+\phi-\alpha)+\alpha \gamma}{\alpha} m_{t}-\left(\chi_{t}-(1-\delta) \chi_{t-1}\right) .
$$

We conjecture the solution

$$
\chi_{t}=k_{h} \chi_{t-1}+\sum_{s=0}^{\infty} b_{s} \mathbb{E}_{t} \hat{\psi}_{t+s}
$$


where $0<k_{h}<1-\delta, b_{0}>0$ and $b_{s}>\tilde{\beta} b_{s-1}$ for all $s \geq 1$. This conjecture implies that

$$
\begin{aligned}
\sum_{s=0}^{\infty} b_{s} \mathbb{E}_{t} \hat{\psi}_{t+s} & =\sum_{s=0}^{\infty} b_{s} \mathbb{E}_{t}\left(\ell_{h} \hat{h}_{t+s}+\ell_{x} \frac{\hat{x}_{t+s}-\tilde{\beta} \mathbb{E}_{t} \hat{x}_{t+s+1}}{\delta}\right) \\
& =\frac{\ell_{x}}{\delta} \sum_{s=0}^{\infty} b_{s} \mathbb{E}_{t} \hat{x}_{t+s}-\frac{\ell_{x}}{\delta} \tilde{\beta} \sum_{s=0}^{\infty} b_{s} \mathbb{E}_{t} \hat{x}_{t+s+1}+\ell_{h} \sum_{s=0}^{\infty} b_{s} \mathbb{E}_{t} \hat{h}_{t+s} \\
& =\frac{\ell_{x}}{\delta} b_{0} \hat{x}_{t}+\frac{\ell_{x}}{\delta} \sum_{s=1}^{\infty}\left(b_{s}-\tilde{\beta} b_{s-1}\right) \mathbb{E}_{t} \hat{x}_{t+s} \\
& +\ell_{h}\left(\sum_{s=0}^{\infty} b_{s}(1-\delta)^{s+1}\right) \hat{h}_{t-1}+\ell_{h} \sum_{s=0}^{\infty}\left(\sum_{\tau=s}^{\infty}(1-\delta)^{\tau} b_{s}\right) \hat{x}_{t+s},
\end{aligned}
$$

so that the coefficients on $\hat{h}_{t-1}$ and $\mathbb{E}_{t} \hat{x}_{t+s}, s \geq 0$ are all strictly positive. Moreover, we can appeal to the market clearing condition (56) to write $\mathbb{E}_{t} \hat{x}_{t+s}=\frac{\omega}{1-\omega} \mathbb{E}_{t} \hat{q}_{t+s}$.

What is left is to verify conjecture (93). The equation (87) is a second-order difference equation in $\chi_{t}$ when $\hat{\psi}_{t}$ and $\Omega_{q t}$ are treated as given. The homogenous form of this second-order difference equation is the same as that for the natural level of asset holdings $h_{t}^{n}$ derived earlier. This establishes that $k_{h}$ is indeed in $(0,1-\delta)$. Furthermore, equations 89-91 form a linear forward-looking system in $\left(\Omega_{q t}, \Omega_{\mu t}, \psi_{t}\right)$ when $\hat{\psi}_{t}$ is treated as given. This implies that the solution in (93) will indeed depend only on forward-looking terms in $\hat{\psi}_{t}$.

Finally, we need to show that $b_{s}>0$ for all $s \geq 0$. We prove this property for $g=0$ and then make a continuity argument to extend it to $g$ small enough. When $g=0$, equation (90) reduces to $\Omega_{q t}=-\frac{1-\omega}{\omega} k_{q} \psi_{t}$. Substituting into (89), we obtain

$$
\begin{aligned}
\psi_{t} & =\hat{\psi}_{t}+\beta k_{h} \mathbb{E}_{t} \psi_{t+1}-\frac{1-\omega}{\omega \delta} k_{q}\left(\psi_{t}-\tilde{\beta} \mathbb{E}_{t} \psi_{t+1}\right) \\
& =\frac{\hat{\psi}_{t}}{1+\frac{1-\omega}{\omega \delta} k_{q}}+\tilde{\beta} \frac{\frac{k_{h}}{1-\delta}+\frac{1-\omega}{\omega \delta} k_{q}}{1+\frac{1-\omega}{\omega \delta} k_{q}} \mathbb{E}_{t} \psi_{t+1} .
\end{aligned}
$$

Now, through equation (89) we also have that

$$
\begin{aligned}
\hat{\psi}_{t}+\frac{\Omega_{q t}-\tilde{\beta} \mathbb{E}_{t} \Omega_{q t+1}}{\delta} & =\psi_{t}-\beta k_{h} \mathbb{E}_{t} \psi_{t+1} \\
& =\sum_{t=0}^{\infty} a_{s} \mathbb{E}_{t} \hat{\psi}_{t+s} .
\end{aligned}
$$

Because $k_{h}<1-\delta$, we have

$$
\tilde{\beta} \frac{\frac{k_{h}}{1-\delta}+\frac{1-\omega}{\omega \delta} k_{q}}{1+\frac{1-\omega}{\omega \delta} k_{q}}=\beta k_{h} \frac{1+\frac{1-\delta}{k_{h}} \frac{1-\omega}{\omega \delta} k_{q}}{1+\frac{1-\omega}{\omega \delta} k_{q}}>\beta k_{h}
$$


and therefore $a_{s}>0$ for all $s \geq 0$.

We now substitute (94) and (93) into the first-order condition (87) to solve for the coefficients $b_{s}$. We obtain:

$$
\begin{aligned}
& \left(\frac{\delta}{\gamma \kappa_{1}} \theta(1-\tilde{\beta})+1+\tilde{\beta}\left(1-\delta-k_{h}\right)\right)\left(k_{h} \chi_{t-1}+\sum_{s=0}^{\infty} b_{s} \mathbb{E}_{t} \hat{\psi}_{t+s}\right) \\
= & \tilde{\beta} \sum_{s=0}^{\infty} b_{s} \mathbb{E}_{t} \hat{\psi}_{t+s+1}+(1-\delta) \chi_{t-1}+\frac{\delta}{\gamma \kappa_{1}} \sum_{t=0}^{\infty} a_{s} \mathbb{E}_{t} \hat{\psi}_{t+s} .
\end{aligned}
$$

Comparing coefficients, we get

$$
\begin{gathered}
s=0:\left(\frac{\delta}{\gamma \kappa_{1}} \theta(1-\tilde{\beta})+1+\tilde{\beta}\left(1-\delta-k_{h}\right)\right) b_{0}=\frac{\delta}{\gamma \kappa_{1}} a_{0} \\
s \geq 1:\left(\frac{\delta}{\gamma \kappa_{1}} \theta(1-\tilde{\beta})+1+\tilde{\beta}\left(1-\delta-k_{h}\right)\right) b_{s}=\tilde{\beta} b_{s-1}+\frac{\delta}{\gamma \kappa_{1}} a_{s} .
\end{gathered}
$$

By an induction argument, these expressions establish that $b_{0}>0$ and $b_{s}>\tilde{\beta} b_{s-1}$ for all $s \geq 1$. 


\section{B Appendix: Excluding labor market clearing from agents' information set}

In this appendix we analyze the model with alternate assumptions about agents' information set under learning. As noted in section 3, in order to sustain an equilibrium with subjective beliefs about asset prices, Walras' law requires that two market clearing conditions be absent from agents' information set. The first of these is of course the market clearing condition for the asset in question, but the second remains a free choice. So far we have followed much of the literature (eg. Adam and Marcet, 2011; Winkler, 2016) and considered the model under the assumption that agents' PLM does not satisfy goods market clearing. One could consider two alternate cases: (i) bond market clearing and asset market clearing are omitted from the agents' information set, or (ii) labor market clearing and asset market clearing are omitted from agents' information set. In the case of (i), a unique stationary equilibrium cannot be derived when bond market clearing is removed from agents' information set. The intuition is straightforward; in such a case agents believe that future bond holdings are unbounded and their behavior becomes explosive. The case of (ii) is non-trivial and we consider its implications here.

As before, under flexible prices the learning model implements the first-best allocation. As a result, the new informational assumptions only effect the asset price and the natural rate of interest in such a case. Figure B.1 plots impulse responses to technology shocks under flexible prices. Relative to the baseline case (figure 2) the response of the asset price is amplified, with a near-negligible impact on the interest rate. Under sticky prices, however, the effect of the change is more pronounced. Figure B.2 plots impulse responses under stick prices, assuming a Taylor '93-type rule. In this case a positive technology shock pushes down inflation. This is a consequence of the impact of the changed information assumption on expected future marginal costs. When agents' information set does not include the labor market clearing condition, then firms do not internalize labor suppy effects when forecasting marginal costs. More specifically, when firms anticipate an increase in future labor demand following the shock, they fail to account for the need for future wages to increase so as to clear the labor market. This consequently pushes down the inflation response relative to baseline case.

Notwithstanding the impact on the inflation process, the learning model retains the dependence of the natural rate of interest on expected asset prices, regardless of whether the goods market or the labor market clearing condition is omitted from agents' information set. Table B.1 shows optimized simple rule coefficients and their performance, 
Figure B.1: Effect of learning under flexible prices.
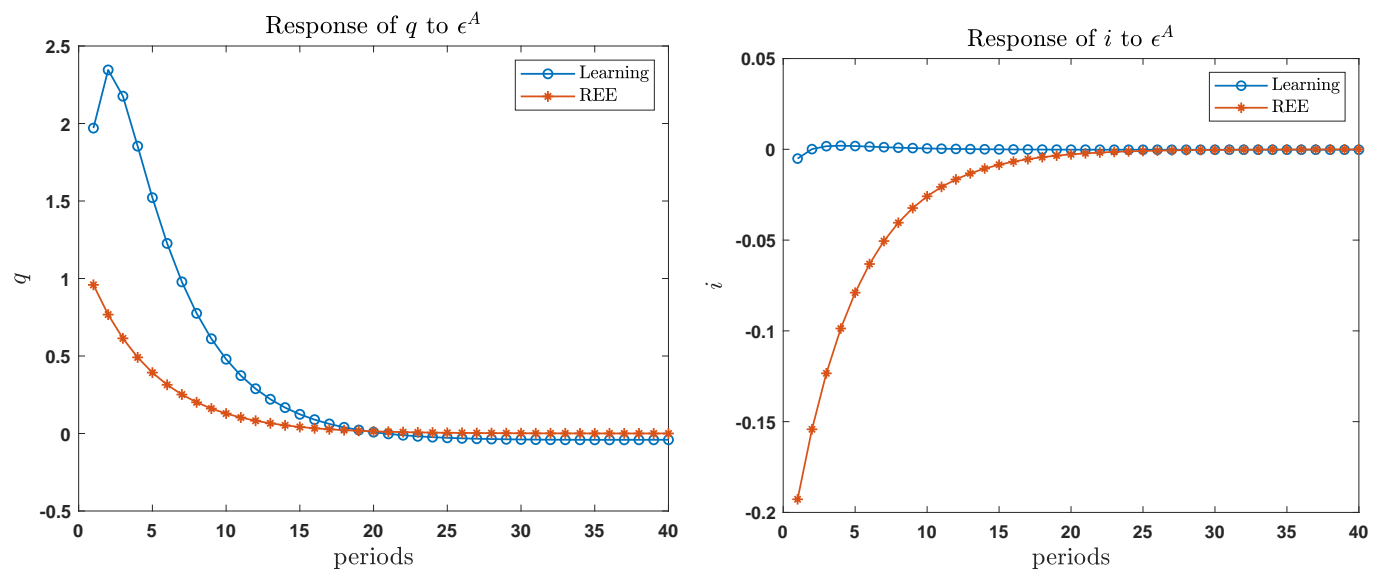

Note: Response to a one standard deviation positive technology shock $\varepsilon_{A t}$. Log percentage points. Model simulated under the assumption that agents' information set does not include asset market clearing or labor market clearing. Flexible prices and zero inflation.

as in section 6. Relative to the baseline case the welfare gains to including asset prices in the policy reaction function are smaller. Indeed, including either the current or lagged asset price value yields only marginal gains (compare row (4) to rows (7), (8) and (10)). However, the optimal simple rule continues to place react positively with prices. When a weighted average of past price growth observations are included in the policy rule (rows (9) and (11)) welfare is increased $1.7 \%$, with the optimized coefficients placing a small positive weight on the asset price term (as was the case with the baseline model in 6). 
Figure B.2: Effect of learning under sticky prices.
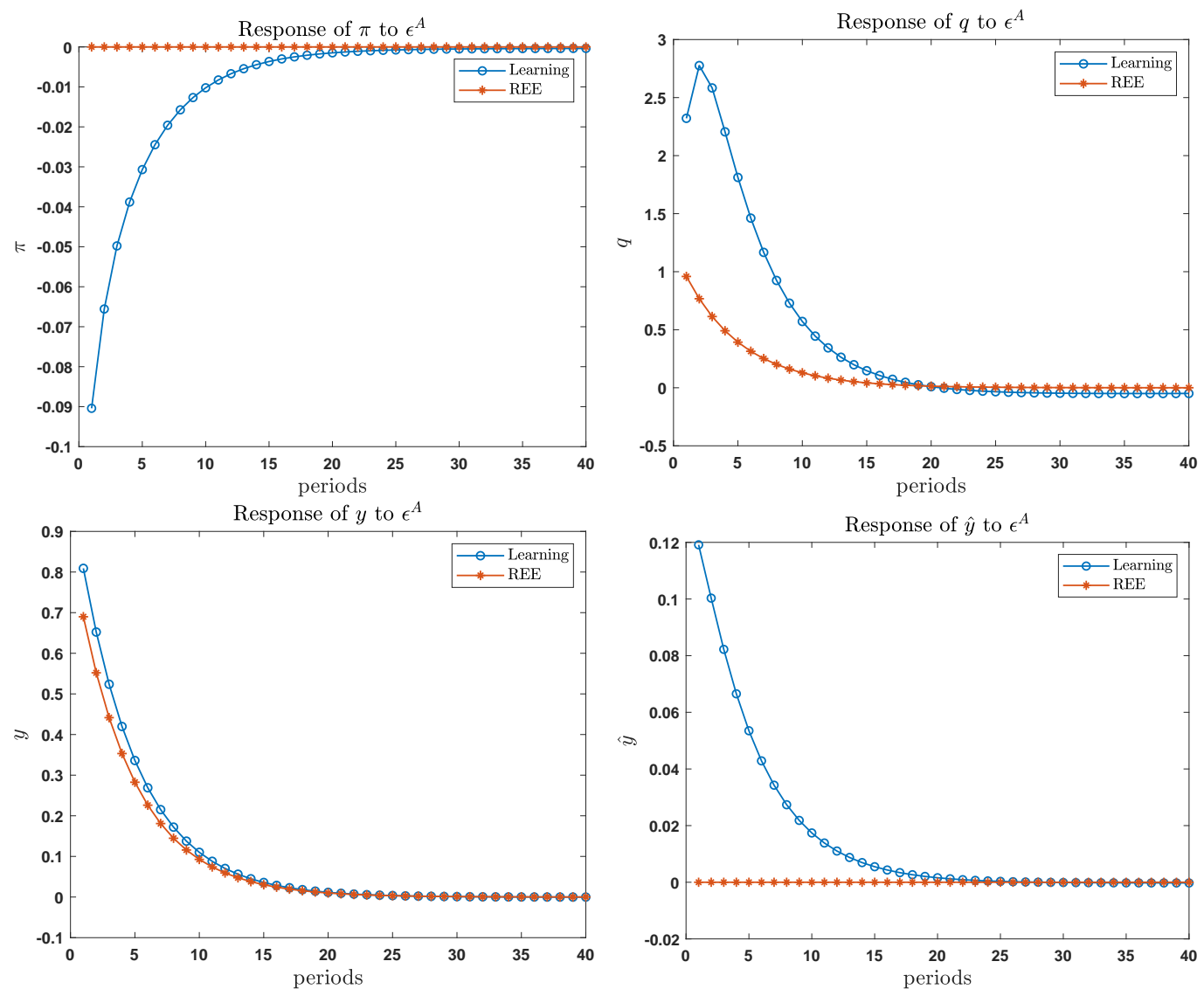

Note: Response to a one standard deviation positive technology shock $\varepsilon_{A t}$. Log percentage points. Model simulated under the assumption that agents' information set does not include asset market clearing or labor market clearing. Sticky prices, Taylor '93 rule. 
Table B.1: Performance of optimized simple rules.

\begin{tabular}{|c|c|c|c|c|c|}
\hline & Rational Expectations & $\sigma\left(\pi_{t}\right)$ & $\sigma\left(\hat{y}_{t}\right)$ & $\sigma\left(\Delta q_{t}\right)$ & $\mathscr{L}$ \\
\hline (1) & $i_{t}=r_{s s}+1.5 \pi_{t}+0.125 \cdot \hat{y}_{t}$ & 0.349 & 0.451 & 0.801 & 3.315 \\
\hline (2) & $\begin{array}{l}i_{t}=\rho_{i}^{*} i_{t-1}+\left(1-\rho_{i}^{*}\right) \cdot\left(r_{s s}+1.5 \pi_{t}+\phi_{y}^{*} \cdot \hat{y}_{t}\right) \\
\left\{\rho_{i}^{*}, \phi_{y}^{*}\right\}=\{0.844,0.331\}\end{array}$ & 0.249 & 0.472 & 0.515 & 1.888 \\
\hline \multirow[t]{2}{*}{ (3) } & $\begin{array}{c}\pi_{t}=\zeta^{*} \eta_{t} \\
\zeta^{*}=0.040\end{array}$ & 0.050 & 0.492 & 1.098 & 0.577 \\
\hline & Learning & $\sigma\left(\pi_{t}\right)$ & $\sigma\left(\hat{y}_{t}\right)$ & $\sigma\left(\Delta q_{t}\right)$ & $\mathscr{L}$ \\
\hline (4) & $\begin{array}{l}i_{t}=\rho_{i}^{*} i_{t-1}+\left(1-\rho_{i}^{*}\right) \cdot\left(r_{s s}+1.5 \pi_{t}+\phi_{y}^{*} \cdot \hat{y}_{t}\right) \\
\left\{\rho_{i}^{*}, \phi_{y}^{*}\right\}=\left\{1.4 \times 10^{-4},-9.3 \times 10^{-4}\right\}\end{array}$ & 0.015 & 0.541 & 2.362 & 0.657 \\
\hline (5) & $\begin{aligned} \pi_{t} & =\zeta^{*} \eta_{t} \\
\zeta^{*} & =0.040\end{aligned}$ & 0.050 & 0.488 & 2.324 & 0.588 \\
\hline (6) & $\begin{array}{l}i_{t}=\rho_{i}^{*} i_{t-1}+\left(1-\rho_{i}^{*}\right) \cdot\left(r_{s s}+1.5 \pi_{t}\right) \\
\rho_{i}^{*}=0\end{array}$ & 0.015 & 0.541 & 2.364 & 0.657 \\
\hline (7) & $\begin{array}{l}\text { BG (1999) w/ asset price } \\
i_{t}=\rho_{i}^{*} i_{t-1}+\left(1-\rho_{i}^{*}\right) \cdot\left(r_{s s}+1.5 \pi_{t}+\phi_{q}^{*} \cdot \log q_{t-1}\right) \\
\quad\left\{\rho_{i}^{*}, \phi_{q}^{*}\right\}=\left\{0,-2.6 \times 10^{-4}\right\}\end{array}$ & 0.016 & 0.540 & 2.359 & 0.656 \\
\hline (8) & $\begin{array}{l}\text { BG (2001) w/ asset price } \\
i_{t}=\rho_{i}^{*} i_{t-1}+\left(1-\rho_{i}^{*}\right) \cdot\left(r_{s s}+1.5 \pi_{t}+\phi_{q}^{*} \cdot \log q_{t}\right) \\
\quad\left\{\rho_{i}^{*}, \phi_{q}^{*}\right\}=\left\{0,2.3 \times 10^{-4}\right\}\end{array}$ & 0.015 & 0.541 & 2.364 & 0.656 \\
\hline (9) & $\begin{array}{l}i_{t}=\rho_{i}^{*} i_{t-1}+\left(1-\rho_{i}^{*}\right) \cdot\left(r_{s s}+1.5 \pi_{t}+\phi_{q}^{*} \cdot \sum_{s=0}^{\infty} \omega^{* s} \Delta \log Q_{t-s}\right) \\
\left\{\rho_{i}^{*}, \phi_{q}^{*}, \omega^{*}\right\}=\{0,0.008,0.105\}\end{array}$ & 0.026 & 0.531 & 2.210 & 0.646 \\
\hline (10) & $\begin{array}{l}\text { FM (2007) w/ asset price } \\
i_{t}=\rho_{i}^{*} i_{t-1}+\left(1-\rho_{i}^{*}\right) \cdot\left(r_{s s}+1.5 \pi_{t}+\phi_{y}^{*} \cdot \hat{y}_{t}+\phi_{q}^{*} \cdot \log q_{t}\right) \\
\quad\left\{\rho_{i}^{*}, \phi_{y}^{*}, \phi_{q}^{*}\right\}=\{0.002,-0.005,0.001\}\end{array}$ & 0.014 & 0.541 & 2.350 & 0.656 \\
\hline (11) & $\begin{array}{l}i_{t}=\rho_{i}^{*} i_{t-1}+\left(1-\rho_{i}^{*}\right) \cdot\left(r_{s s}+1.5 \pi_{t}+\phi_{y}^{*} \cdot \hat{y}_{t}+\phi_{q}^{*} \cdot \sum_{s=0}^{\infty} \omega^{* s} \Delta \log Q_{t-s}\right) \\
\left\{\rho_{i}^{*}, \phi_{y}^{*}, \phi_{q}^{*}, \omega^{*}\right\}=\{0,-0.002,0.008,0.126\}\end{array}$ & 0.026 & 0.531 & 2.208 & 0.646 \\
\hline
\end{tabular}

Note: Model simulated under the assumption that agents' information set does not include asset market clearing or labor market clearing. 